\title{
How Solvent Dynamics Controls the Schlenk Equilibrium of Grignard Reagents: A Computational Study of $\mathrm{CH}_{3} \mathrm{MgCl}$ in Tetrahydrofuran
}

\author{
Raphael M. Peltzer, ${ }^{\dagger}$ Odile Eisenstein, ${ }^{\dagger}{ }^{\dagger}$ Ainara Nova, ${ }^{*}{ }^{\dagger}$ and Michele Cascella ${ }^{*}{ }^{\dagger}$ \\ ${ }^{\dagger}$ Department of Chemistry and Centre for Theoretical and Computational Chemistry (CTCC), University of Oslo, Postbox 1033 \\ Blindern, 0315 Oslo, Norway \\ ${ }^{\ddagger}$ Institut Charles Gerhardt, UMR 5253 CNRS-Université de Montpellier, Université de Montpellier, cc 1501, Place E. Bataillon, \\ 34095 Montpellier, France
}

\section{Supporting Information}

\begin{abstract}
The Schlenk equilibrium is a complex reaction governing the presence of multiple chemical species in solution of Grignard reagents. The full characterization at the molecular level of the transformation of $\mathrm{CH}_{3} \mathrm{MgCl}$ into $\mathrm{MgCl}_{2}$ and $\mathrm{Mg}\left(\mathrm{CH}_{3}\right)_{2}$ in tetrahydrofuran (THF) by means of ab initio molecular dynamics simulations with enhanced-sampling metadynamics is presented. The reaction occurs via formation of dinuclear species bridged by chlorine atoms. At room temperature, the different chemical species involved in the reaction accept multiple solvation structures, with two to four THF molecules that can coordinate the $\mathrm{Mg}$ atoms. The energy difference between all dinuclear solvated structures is lower than $5 \mathrm{kcal} \mathrm{mol}^{-1}$. The solvent is shown to be a direct key player driving the Schlenk mechanism. In particular, this study illustrates how the most stable symmetrically solvated dinuclear species,

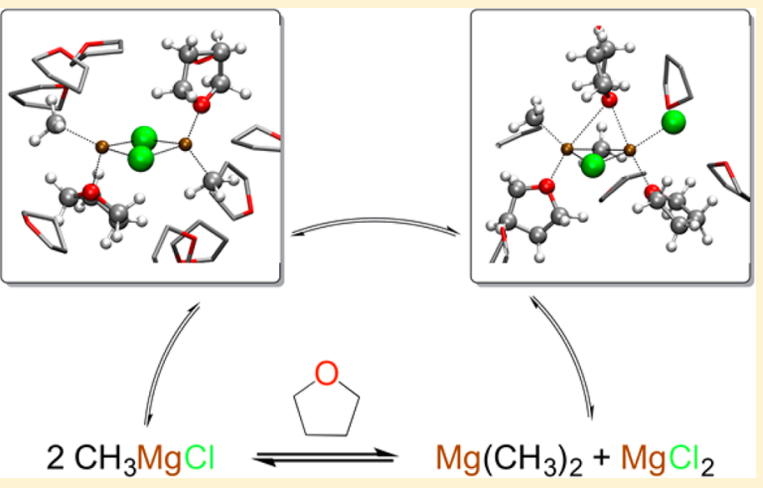
(THF) $\mathrm{CH}_{3} \mathrm{Mg}(\mu-\mathrm{Cl})_{2} \mathrm{MgCH}_{3}$ (THF) and (THF) $\mathrm{CH}_{3} \mathrm{Mg}(\mu-\mathrm{Cl})\left(\mu-\mathrm{CH}_{3}\right) \mathrm{MgCl}(\mathrm{THF})$, need to evolve to less stable asymmetrically solvated species, (THF) $\mathrm{CH}_{3} \mathrm{Mg}(\mu-\mathrm{Cl})_{2} \mathrm{MgCH}_{3}$ (THF) $)_{2}$ and (THF) $\mathrm{CH}_{3} \mathrm{Mg}(\mu-\mathrm{Cl})\left(\mu-\mathrm{CH}_{3}\right) \mathrm{MgCl}(\mathrm{THF})_{2}$, in order to yield ligand exchange or product dissociation. In addition, the transferred ligands are always departing from an axial position of a pentacoordinated $\mathrm{Mg}$ atom. Thus, solvent dynamics is key to successive $\mathrm{Mg}-\mathrm{Cl}$ and $\mathrm{Mg}-\mathrm{CH}_{3}$ bond cleavages because bond breaking occurs at the most solvated $\mathrm{Mg}$ atom and the formation of bonds takes place at the least solvated one. The dynamics of the solvent also contributes to keep relatively flat the free energy profile of the Schlenk equilibrium. These results shed light on one of the most used organometallic reagents whose structure in solvent remains experimentally unresolved. These results may also help to develop a more efficient catalyst for reactions involving these species.
\end{abstract}

\section{INTRODUCTION}

In 1900, the presentation by Victor Grignard of a new compound, completely soluble in ether and formed upon reaction of magnesium with alkyl halides, ${ }^{1}$ paved the way to establish one of the most widely used organometallic reagents in organic synthesis, worth the Noble prize in 1912 . $^{2}$ The socalled Grignard reagent, with nominal formula $\mathrm{RMgX}$, is used in nucleophilic addition or substitution reactions, taking advantage of the enriched electron density in the $\mathrm{R}$ group coordinated to the $\mathrm{Mg}$ atom.

Initial limitations to the direct use of this reagent were found due to its relatively modest tolerance to different functional groups compared to that of corresponding boron and zinc metals. However, the use of $\mathrm{Ni}$ catalysts in coupling reactions using the Grignard reagent, independently developed by Corriu and Massé and Kumada and Tamao, increased the relevance of this reagent. ${ }^{3,4}$ Nowadays, interest in the functionalization of phenol-based derivatives involving earth-abundant metal catalysts and the development of efficient synthetic protocols allowing work at very mild conditions and with large functional tolerance make organomagnesium reagents very attractive. ${ }^{5-12}$

Despite the use of Grignard reagents in organic synthesis, their molecular structure in solution has remained elusive so far, even if considerable research effort has been spent on this topic. In an illuminating essay, Seyferth described the difficulties in characterizing the structures of Grignard reagents, which can be affected by both the solvent, and the halide and organic groups bonded to $\mathrm{Mg} .{ }^{13}$ Solid-state structures determined by X-ray diffraction studies revealed a diversity of coordination modes for $\mathrm{Mg}$, and of nuclearity for the molecular system. Tetrahedral coordination is commonly observed in crystals structures obtained from ether solutions as $\operatorname{EtMgBr}\left(\mathrm{OEt}_{2}\right)_{2}$, ${ }^{14}$ where two molecules of solvent are bound to $\mathrm{Mg}$. Instead, both trigonal-bipyramidal and square-pyramidal structures were found for $\mathrm{CH}_{3} \mathrm{MgBrTHF}_{3}$ when working in tetrahydrofuran (THF) solvent. ${ }^{15} \mathrm{X}$-ray data of aggregates of two $\mathrm{EtMg}_{2} \mathrm{Cl}_{3}$

Received: March 30, 2017

Published: March 30, 2017 
moieties showed a greater than four coordination for the $\mathrm{Mg}$ centers. ${ }^{16,17}$ Due to lattice packing restrictions, the structures of Grignard reagents observed in the crystalline solid state may not be necessarily representative of the stable species present in solution. Investigations using molecular weight, ${ }^{18}$ calorimetric measurements, ${ }^{19}$ and NMR and IR spectroscopy ${ }^{20}$ support in fact the existence of structures other than those detected by Xray crystallography.

Determination of the structures of Grignard reagents in solution is particularly complex because of the presence of multiple chemical species at thermodynamic equilibrium. This complication has been evident since 1929, when Schlenk father and son ${ }^{21}$ proposed that redistribution of ligands yielding $\mathrm{MgR}_{2}$ and $\mathrm{MgX}_{2}$ from $\mathrm{RMgX}$ could take place (original Schlenk equilibrium in Scheme 1). At present, it is commonly

Scheme 1. Schlenk Equilibria

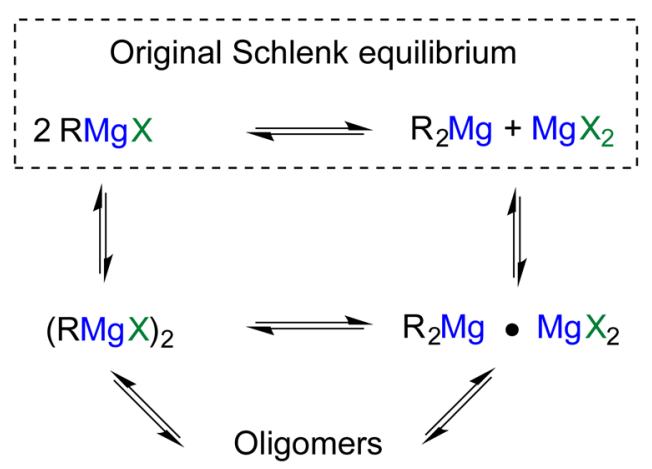

Generalized Schlenk equilibrium

recognized that the halide groups in $\mathrm{RMgX}$ and $\mathrm{MgX}_{2}$ tend to form bridges between magnesium atoms to yield dimers and oligomeric structures, which are in equilibrium with monomeric species (generalized Schlenk equilibrium in Scheme 1). This causes association between the various moieties, eventually favoring ligand exchange. The degree of association among the $\mathrm{Mg}$ centers is dependent on the solvent, as shown by Ashby and Walker, who found a degree of association of around $\sim 1$ in THF and between 1 and 4, depending on the nature of $\mathrm{R}$ and $\mathrm{X}$, in diethyl ether. ${ }^{22}$ Further studies suggested that some complex equilibrium between $\mathrm{RMgCl}(\mathrm{THF})_{n}, \mathrm{MgR}_{2}(\mu$ $\mathrm{Cl})_{2} \mathrm{Mg}(\mathrm{THF})_{5 / 4}$ and $\mathrm{RMg}_{2}(\mu \text {-Cl })_{3}(\mathrm{THF})_{5}$ better describes the traditional Schlenk equilibrium. ${ }^{23,24}$

Given the complexity of the problem, computational modeling offers an excellent tool to determine in detail the chemical nature of the species involved in the Schlenk equilibrium. In the past, examination of the Cambridge Crystallographic Database and density functional theory $(\mathrm{DFT})^{25-27}$ calculations for isolated molecules led to establishing the overwhelming prevalence of structures with two over three bridging ligands and a preference for halide over alkyl ligands in that position. Moreover, they observed that the maximum stabilizing effect of the coordinating solvent is obtained for dimeric moieties. ${ }^{28}$ Including the solvent as a continuum model in a systematic way and combining generalized valence bond, second-order Møller-Plesset perturbation theory (MP2), and DFT calculations indicated that radical and charged species may be present at equilibrium, although in small concentrations. ${ }^{29}$ Explicit solvent was limited to the first coordination sphere of the $\mathrm{Mg}$ atom, and in many cases, the total number of ligands at $\mathrm{Mg}$ including the solvent was fixed to four. However, both crystallographic ${ }^{30-32}$ and computational studies ${ }^{33}$ showed that $\mathrm{Mg}$ could expand its coordination sphere over more than four ligands, up to hexacoordination. This limitation is probably even more inappropriate when trying to understand the dynamic processes involved in the Schlenk equilibrium (Scheme 1).

In consideration of the longstanding and recently renewed importance of Grignard in organic synthesis, ${ }^{34-36}$ it is important to reach a better understanding of its structure and dynamic behavior in solvent. In this respect, dynamic modeling approaches may constitute the optimal choice for an accurate description of the Grignard reagent. In the past decades, ab initio molecular dynamics simulations (AIMD) have been shown to be especially appropriate to study processes in the liquid phase. ${ }^{37,38}$ For example, this technique was used to study structural properties of various metal ions in solution, including $\mathrm{Na},{ }^{39} \mathrm{Mg},{ }^{40,41}$ or $\mathrm{Co}$ and $\mathrm{Ag} .{ }^{42}$ In addition, AIMD with enhanced sampling methods were effectively used to provide an accurate description of solvent effects in various organic ${ }^{43,44}$ and organometallic reactions. ${ }^{45,46}$ Larger metallo-organic systems have also been been treated by coupling AIMD to molecular mechanics schemes. ${ }^{47}$ This approach was used to describe, for example, electronic solute-solvent coupling in photoexcitation dynamics of ruthenium metallo-organic compounds, ${ }^{48}$ the reaction mechanisms of hydrolysis in zinc $\beta$ lactamases, ${ }^{49,50}$ the redox properties of copper in azurin, ${ }^{51}$ the functional role of $\mathrm{Mg}^{2+}$ ions in ribonuclease $\mathrm{H},{ }^{52}$ and the design of organoruthenium anticancer complexes. ${ }^{53}$

In this work, this methodology was used to investigate the equilibria that take place when $\mathrm{CH}_{3} \mathrm{MgCl}$, a model of the Grignard reagent, is dissolved in THF. Our study was also complemented by DFT static calculations on selected structures identified as minima by ab initio molecular dynamics. The data presented in this work show that multiple structures with different solvation patterns are in equilibrium and evidence how the dynamic exchange of solvent molecules in the $\mathrm{Mg}$ coordination sphere is key to evolution from the reactant to product in the Schlenk equilibrium.

\section{COMPUTATIONAL METHODS}

System Setup. The Schlenk equilibrium was investigated through a set of simulations describing monomeric reactants, monomeric products, and different intermediate dimeric states.

Monomeric Species. We built three different systems, each containing 1 molecule of either $\mathrm{CH}_{3} \mathrm{MgCl}, \mathrm{MgCl}_{2}$, or $\mathrm{Mg}\left(\mathrm{CH}_{3}\right)_{2}$ surrounded by 25 molecules of THF in a periodic box of dimensions $15.0 \times 15.0 \times 15.0 \AA^{3}$. The initial coordinates of THF were obtained from a previous 20 ps long equilibration run in a similar box containing the pure solvent. The number of solvent molecules was set to be consistent with the experimental density of THF at room temperature. ${ }^{54}$ All systems were first relaxed for 15 ps in the microcanonical ensemble at energies matching an average temperature of $300 \mathrm{~K}$. Relaxation at the target temperature was performed using a canonical sampling/velocity rescaling (CSVR) thermostat with a time constant of $10 \mathrm{fs}$ until the temperature of the system oscillated around the target value. Production runs were simulated in the NVT ensemble at $300 \mathrm{~K}$. The Nosé-Hoover chain thermostat with a chain length of 3 and time constant of 1 ps was used for data production. ${ }^{55-57}$

Dimeric Species. The $\left(\mathrm{MgCH}_{3} \mathrm{Cl}\right)_{2}$ species were simulated in an orthorhombic periodic box of dimensions $25.2 \times 15.0 \times$ 
15.0 $\AA^{3}$, containing 42 THF molecules (Figure 1). A larger box of dimensions $25.2 \times 20.0 \times 20.0 \AA^{3}$ with $74 \mathrm{THF}$ molecules

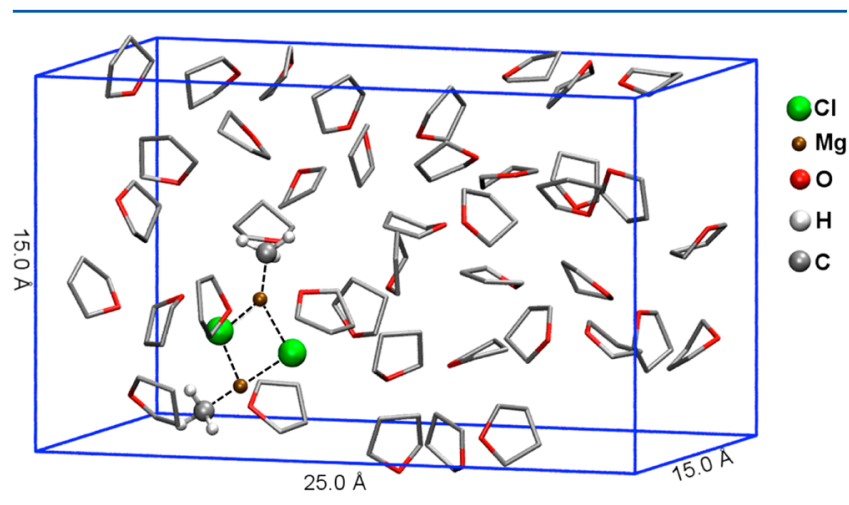

Figure 1. Simulation box used in this study. The atoms of the Grignard reagent are represented by spheres and the THF solvent molecules by sticks in licorice and red. Hydrogen atoms of THF are not shown for clarity.

was also simulated to verify that there is no significant bias due to finite-size effects (see the Supporting Information). The systems were thermalized following the same protocol as that described for the monomers.

Ab Initio Molecular Dynamics Simulations. The electronic problem was solved by $\mathrm{DFT}^{25,26}$ using the Perdew-Burke-Ernzerhof approximation to the exchangecorrelation functional. ${ }^{58}$ Kohn-Sham orbitals were expanded over mixed Gaussian and plane-wave basis functions. ${ }^{59}$ The DZVP basis set for first and second row elements and $\mathrm{Mg}$ and a molecularly optimized basis set for the chlorine atoms were employed. ${ }^{60}$ The auxiliary plane-wave basis set was expanded to a 200 Ry cutoff. The core electrons were integrated using pseudopotentials of Goedecker-Teter-Hutter type. ${ }^{61}$ Dispersion forces were accounted for using the D3 Grimme approximation. $^{62}$ AIMD simulations were run over the BornOppenheimer surface, with a time step of $0.25 \mathrm{fs}$, optimizing the energy gradient to a threshold of $10^{-5}$ au.

Free-Energy Calculations. Exploration of the conformational and reactive landscape and determination of the corresponding free-energy surface (FES) were performed by coupling AIMD to metadynamics simulations. ${ }^{37,63}$ Solvation of different chemical species observed during the AIMD runs, as well as the transmetalation reaction, was investigated by independent metadynamics runs. All collective variables (CVs) employed in this study were defined as the coordination number of specific ligand species to individual $\mathrm{Mg}$ atoms. The coordination number of a species $\mathrm{X}$ around $\mathrm{Mg}$ at a given time $t$ $(\mathrm{CN}[\mathrm{X}](t))$ was evaluated according to the formula shown in eq 1 , as defined in previous works ${ }^{38}$

$$
\mathrm{CN}[\mathrm{X}](t)=\sum_{i}^{N_{x}} \frac{1-\left(\frac{d_{i}(t)}{d_{0}}\right)^{p}}{1-\left(\frac{d_{i}(t)}{d_{0}}\right)^{q}}
$$

where $N_{\mathrm{X}}$ is the number of species X present in the system, $d_{i}$ is the distance of the $i^{\text {th }}$ atom $\mathrm{X}$ from $\mathrm{Mg}$, and $d_{0}, p$, and $q$ are free parameters (see the Supporting Information).

The time-dependent bias potential was formed by sets of Gaussians of $0.25 \mathrm{kcal} \mathrm{mol}^{-1}$ height and 0.04 width for coordination variables and added every 50 steps of AIMD for the dichloride bridged system. Additional details of the metadynamics parameters used as well as the associated errors are given in Table S1 of the Supporting Information.

The metadynamics simulations convergence was confirmed by checking that the calculations reached the diffusion limit within their wall constraints; statistical errors, computed according to refs 64 and 65 , are within $1-3 k T$ (see the Supporting Information).

AIMD runs were computed using the QUICKSTEP ${ }^{66,67}$ module of the CP2K 2.5.1 package. Trajectory analysis was performed using the tools available in the VMD 1.9.2 package. $^{68}$

Static Calculations and Electronic Structure Analysis. Chemically relevant geometries sampled by AIMD were fully optimized at the DFT(PBE+GD3) level by using the Gaussian09 software package. ${ }^{69} \mathrm{Mg}, \mathrm{C}, \mathrm{H}$, and $\mathrm{O}$ were described with the all-electron double- $\zeta \quad 6-31+\mathrm{G}^{* *}$ basis set. $^{70-72}$ Vibrational frequencies were computed analytically to verify that the stationary points found were energy minima. In addition to the solvent molecules bound to $\mathrm{Mg}$, implicit solvation was modeled by using the SMD solvation model. ${ }^{73}$ In selected cases, Gibbs energies were obtained for $T=298.15 \mathrm{~K}$ and $p=1 \mathrm{~atm}$. In the bimolecular steps, these energies were corrected for the $1 \mathrm{M}$ standard state $(T=298.15 \mathrm{~K}$ and $p=$ $24.465 \mathrm{~atm})$. Donor-acceptor interactions were explored by means of natural bond orbital (NBO) calculations (NBO6 version). ${ }^{74}$ The nature of these interactions was determined by computing the associated natural localized molecular orbitals (NLMOs). ${ }^{75}$

\section{RESULTS}

We restricted our investigation to monomers and dinuclear species, excluding higher aggregation states, because experimental studies showed that in THF the aggregation is very low, mainly consisting of monomeric species. ${ }^{22}$

Monomeric Structures. The solvation of $\mathrm{CH}_{3} \mathrm{MgCl}$, $\mathrm{Mg}\left(\mathrm{CH}_{3}\right)_{2}$, and $\mathrm{MgCl}_{2}$ species was investigated over 40 ps of AIMD simulations at $300 \mathrm{~K} . \mathrm{CH}_{3} \mathrm{MgCl}$ and $\mathrm{Mg}\left(\mathrm{CH}_{3}\right)_{2}$ were found with only two THF molecules in the solvation sphere of $\mathrm{Mg}$ and tetrahedral coordination at this atom (Figure 2). On

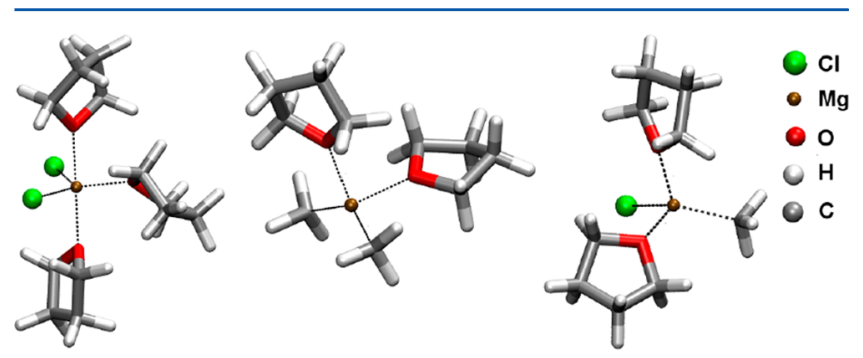

Figure 2. Most likely solvation structures for $\mathrm{MgCl}_{2}$ (left), $\mathrm{Mg}\left(\mathrm{CH}_{3}\right)_{2}$ (middle), and $\left(\mathrm{CH}_{3}\right) \mathrm{MgCl}$ (right). The dotted black lines represent coordination of the ligands to the $\mathrm{Mg}$ center.

the contrary, both tetrameric and pentameric coordination were found for $\mathrm{MgCl}_{2}$. The nature of the solvation of $\mathrm{MgCl}_{2}$ was then further investigated by metadynamics simulations, using the coordination number of oxygen atoms of THF to $\mathrm{Mg}$ as the $\mathrm{CV}$. These simulations showed that the most likely solvation state is $\mathrm{MgCl}_{2}(\mathrm{THF})_{3}$ arranged in trigonal-bipyramidal coordination at $\mathrm{Mg}$. $\mathrm{MgCl}_{2}(\mathrm{THF})_{3}$ is $\sim 1.6$ and $\sim 2.8 \mathrm{kcal}$ $\mathrm{mol}^{-1}$ more stable than the tetrahedral or octahedral complexes with two and four coordinating THF molecules, respectively. Thus, at room temperature, the different solvation states are in 
B

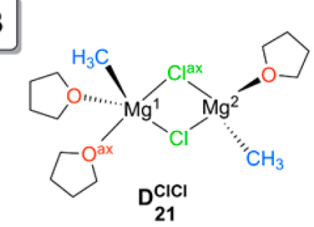

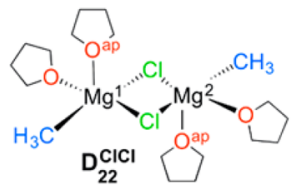

A

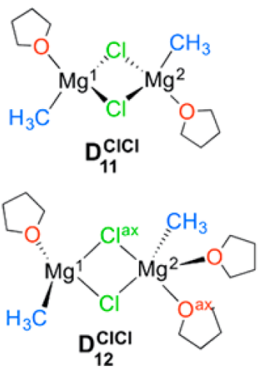

D

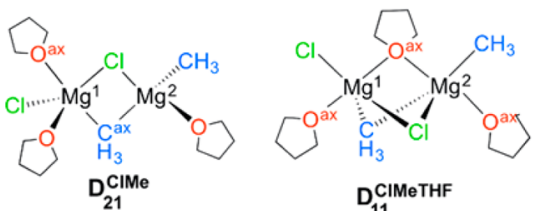<smiles>C1CCCC1</smiles>

3

נ)

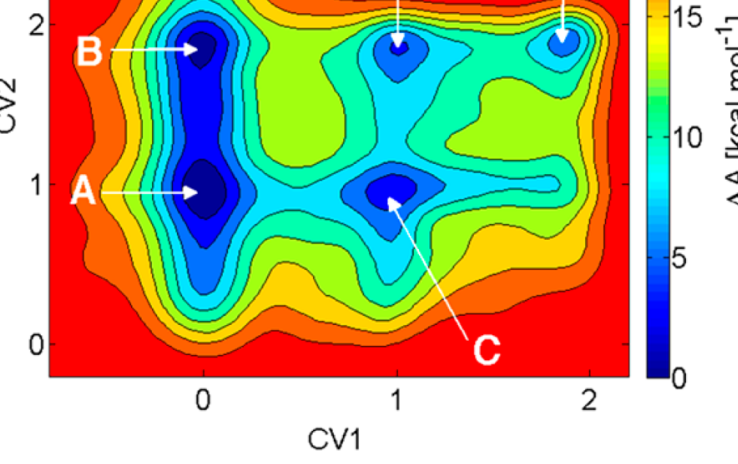

E

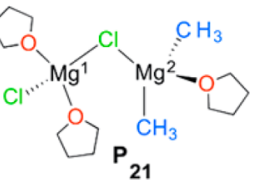

c

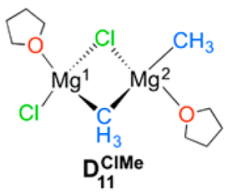

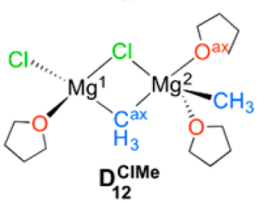

Figure 3. FES of the Schlenk equilibrium. The CVs for this representation are the difference in $\mathrm{Mg}-\mathrm{CH}_{3}$ coordination number between $\mathrm{Mg}^{2}$ and $\mathrm{Mg}^{1}(\mathrm{CV} 1)$ and the THF coordination number to $\mathrm{Mg}^{1}(\mathrm{CV} 2)$. The chemical structures drawn in the figure depict the most representative species obtained for wells A-E.

a

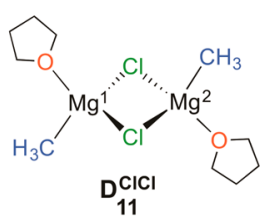

b

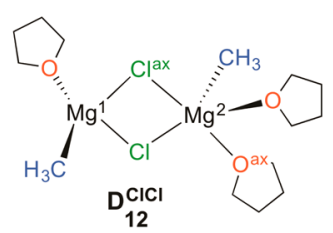

c]

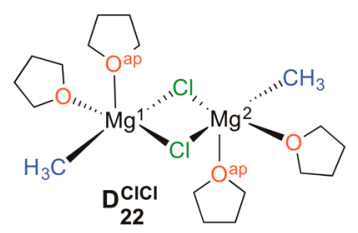

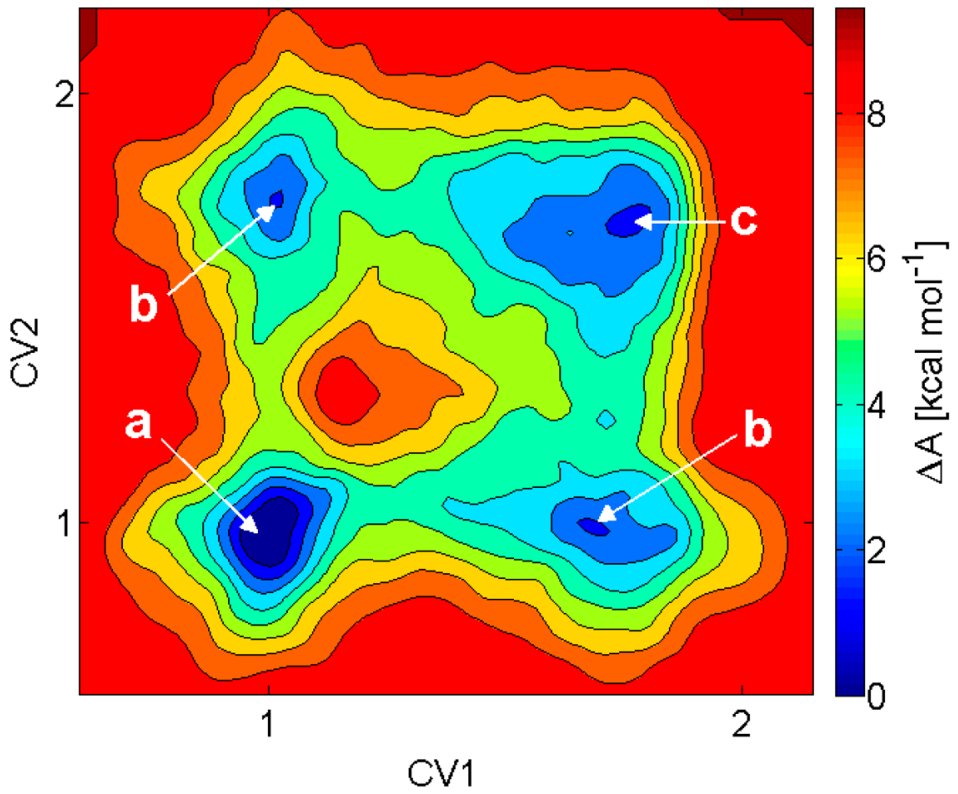

CV1

Figure 4. Solvated $\mathbf{D}^{\mathrm{ClCl}}$ structures found by metadynamics simulations (left) and the corresponding FES (right). CV1 and CV2 are defined as the coordination numbers of THF at $\mathrm{Mg}^{1}$ and $\mathrm{Mg}^{2}$, respectively, following eq 1 . The two minima b correspond to the chemically equivalent $\mathbf{D}_{12}^{\mathrm{ClCl}}$ and $\mathbf{D}_{21}^{\mathrm{ClCl}}$ structures. Only $\mathbf{D}_{12}^{\mathrm{ClCl}}$ is shown for simplicity.

equilibrium in solution in a 0.07:1.0:0.01 ratio for the di-, tri-, and tetra-solvated complexes, yielding an average $\mathrm{MgCl}_{2}(\mathrm{THF})_{x}$ solvation with value $x=2.9$.

DFT optimization of the structures located as minima on the FES showed that they are also minima on the potential energy surface (PES) with similar structural features (these structures are shown in Figure 2). NBO analysis on these optimized structures showed higher electron donation of $\mathrm{CH}_{3}$ to $\mathrm{Mg}$ compared to $\mathrm{Cl}$. This is shown by the $\mathrm{Mg}$ contribution on the lone pairs' NLMOs of $\mathrm{CH}_{3}$ and $\mathrm{Cl}\left(\chi^{\mathrm{Mg}}\right)$, which are 10.2 and $5.3 \%$, respectively, in $\mathrm{CH}_{3} \mathrm{MgCl}$ (see Figure $\mathrm{S} 1$ and Table $\mathrm{S} 1$ for further details). This may explain the need for additional coordination of THF in $\mathrm{MgCl}_{2}$ to improve the screening of the Mg charge.

Dinuclear Structures. The formation of dinuclear species was first studied by performing an AIMD simulation at $300 \mathrm{~K}$ starting from two molecules of $\mathrm{CH}_{3} \mathrm{MgCl}$ placed with their respective $\mathrm{Mg}$ atoms at a distance of $9.5 \AA$. In order to 
accelerate the dimerization, a bias restraining potential to induce the approach of the two molecules was used (see the Computational Methods section). A dimeric structure with two bridging chlorides was formed as soon as the two $\mathrm{Mg}$ atoms were at a distance of $5.5 \AA$.

$\mathrm{Cl} / \mathrm{CH}_{3}$ Exchange Process. Chloride/methyl exchange between the two $\mathrm{Mg}$ centers was investigated combining AIMD and metadynamics simulations, using as CVs the THF solvation number on one arbitrary $\mathrm{Mg}$ atom $(\mathrm{CV} 1)$ and the difference in methyl coordination between the two $\mathrm{Mg}$ atoms (CV2). The CVs where chosen to monitor the free energy change upon methyl transfer between the $\mathrm{Mg}$ atoms as a function of the local solvation of $\mathrm{Mg}$.

The resulting FES (Figure 3) shows five separated wells (A, B, C, D, and E) that can be classified according to the nature of the $\mathrm{Mg}$ bridging groups. The most representative structures captured in each well are shown in Figure 3. Wells A and B correspond to dichloride bridged dinuclear species, $\mathbf{C}$ and $\mathbf{D}$ correspond to the mixed $\mathrm{Me}$ and $\mathrm{Cl}$ bridged species, and $\mathbf{E}$ encloses monochloride bridged structures of formula $\mathrm{ClMg}(\mu$ $\mathrm{Cl}) \mathrm{MgMe}_{2}$. While wells $\mathbf{A}$ and $\mathbf{B}$ represent the structures of the reactants, well $\mathbf{E}$ represents the preproduct state prior to final dissociation into $\mathrm{MgCl}_{2}$ and $\mathrm{Mg}\left(\mathrm{CH}_{3}\right)_{2}$.

We introduce a notation for describing the nature of the dimer $\mathbf{D}$. The notation $\mathbf{D}_{i j}^{\mathbf{X Y}}$ stands for dimer (D) where $i$ and $j$ are the numbers of THF molecules on $\mathrm{Mg}^{1}$ and $\mathrm{Mg}^{2}$, respectively, and $\mathrm{X}$ and $\mathrm{Y}$ describe the nature of the bridging ligands. $\mathrm{D}^{\mathrm{XY}}$ describes the entire family of $\mathrm{X}$ and $\mathrm{Y}$ bridging species regardless of the number of THF molecules on either $\mathrm{Mg}$. The FES plot in Figure 3 shows that the ensemble of $\mathbf{D}^{\mathrm{ClCl}}$ structures is more stable by $\sim 3.5 \mathrm{kcal} \mathrm{mol}^{-1}$ than the one for $\mathrm{D}^{\mathrm{ClMe}}$. In addition, the FES shows a clear path connecting the A-E wells, thus giving information on the ligand exchange reaction. The transformation from wells $\mathbf{A}$ and $\mathbf{B}$ to $\mathbf{D}$ goes preferentially via well $\mathbf{C}$, while exchange directly connecting $\mathbf{B}$ to $\mathbf{D}$ does not constitute a similarly viable path. The energy barriers for the $\mathbf{A}-\mathbf{C}$ and $\mathbf{C}-\mathbf{D}$ transition are $\sim 8$ and $\sim 6 \mathrm{kcal}$ $\mathrm{mol}^{-1}$, respectively, while the free energy barrier between $\mathbf{B}$ and $\mathbf{D}$ is $13 \mathrm{kcal} \mathrm{mol}^{-1}$ higher than that of well $\mathbf{A}$. The preference for this path was analyzed by studying more closely the solvation structures of $\mathrm{D}^{\mathrm{ClCl}}$ and $\mathrm{D}^{\mathrm{ClMe}}$.

Solvation of Dichloride Bridged Structures. The accessible solvation states of $\mathbf{D}^{\mathrm{ClCl}}$ in the $\mathbf{A}$ and $\mathbf{B}$ wells (Figure 3) were investigated by metadynamics simulations using the coordination number of the oxygen atoms of THF to each of the $\mathrm{Mg}$ atoms as CVs. The simulations revealed the existence of three solvation states, corresponding to distinct free-energy minima reported in Figure $4 a-c$. The solvation state with the lowest free energy corresponds to a symmetric dimeric structure in which each $\mathrm{Mg}$ atom is solvated by a single THF $\left(\mathbf{D}_{11}^{\mathrm{ClCl}}\right)$. The second most stable solvation state, only 1.3 $\mathrm{kcal} \mathrm{mol}^{-1}$ higher in energy, corresponds to another symmetric adduct with two THF molecules coordinating each $\mathrm{Mg}\left(\mathbf{D}_{22}^{\mathrm{ClCl}}\right)$. In the later, each $\mathrm{Mg}$ is five-coordinated. The interconversion between these two structures occurs through a metastable asymmetric solvation state $\mathbf{D}_{12}^{\mathrm{ClCl}}$ with one THF solvent on one $\mathrm{Mg}$ and two on the other. This asymmetric solvation state $\mathbf{D}_{12}^{\mathrm{ClCl}}$, which is $2.7 \mathrm{kcal} \mathrm{mol}^{-1}$ higher in energy than $\mathbf{D}_{11}^{\mathrm{ClCl}}$, is expected to be statistically present in $1 \%$ of room-temperature samples, also taking into account degenerate states. Higher solvation states with three THF molecules in the first solvation shell of a single $\mathrm{Mg}$ center are more than $5 \mathrm{kcal} \mathrm{mol}^{-1}$ higher in energy than $D_{11}^{\mathrm{ClCl}}$ and therefore are expected to be present only in minor amounts in room-temperature samples. Both the relative stability and activation energies for the interchange between $\mathbf{D}_{11}^{\mathrm{ClCl}}, \mathbf{D}_{12}^{\mathrm{ClCl}}$, and $\mathbf{D}_{22}^{\mathrm{ClCl}}$ are low (less than $5 \mathrm{kcal}$ $\mathrm{mol}^{-1}$ ), implying fast interconversion between the different structures at room temperature.

Analysis of the structural changes from $D_{11}^{\mathrm{ClCl}}$ to $\mathrm{D}_{12}^{\mathrm{ClCl}}$ showed that the addition of THF to $\mathrm{Mg}^{2}$ (Figure 4) occurs always anti to one of the chlorides, producing local trigonal-bipyramidal coordination with the bridging Cl's in axial and equatorial positions. AIMD simulations indicated significant lengthening of the $\mathrm{Mg}-\mathrm{Cl}_{\mathrm{ax}}$ bond relative to the $\mathrm{Mg}-\mathrm{Cl}_{\mathrm{eq}}$ one. Reversible cleavage of the axial $\mathrm{Cl}-\mathrm{Mg}$ bond and the consequential formation of transient single chloride bridged structures were observed during the analysis of AIMD trajectories. In order to analyze the influence of the solvent on $\mathrm{Mg}-\mathrm{Cl}$ cleavage, the statistical distribution of the $\mathrm{Mg}-\mathrm{Cl}$ bond lengths in $\mathbf{D}_{11}^{\mathrm{ClCl}}$, $\mathbf{D}_{12}^{\mathrm{ClCl}}$, and $\mathbf{D}_{22}^{\mathrm{ClCl}}$ was computed (Figure 5). As expected, an increase in solvation is associated with statistical elongation of the $\mathrm{Mg}-\mathrm{Cl}$ bonds.
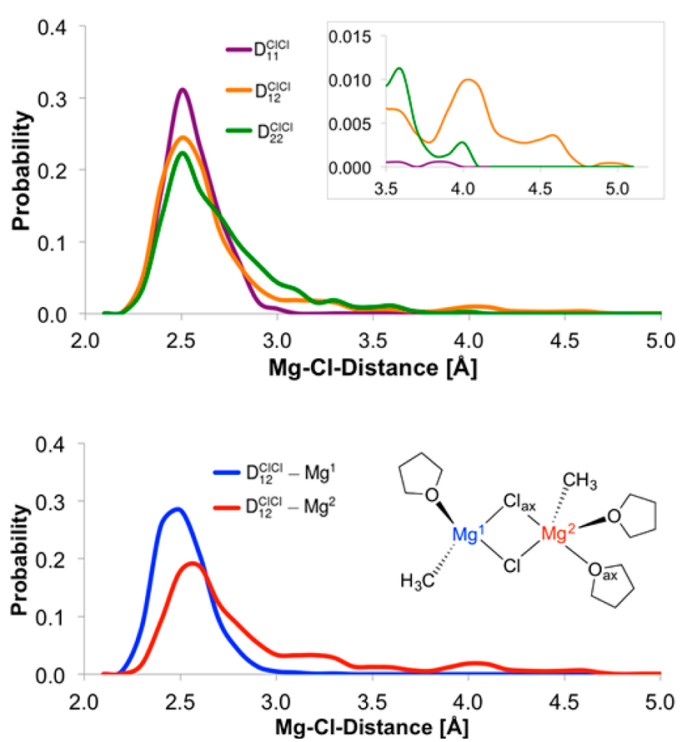

Figure 5. (Top) $\mathrm{Mg}-\mathrm{Cl}$ distance distributions in $\mathrm{D}^{\mathrm{ClCl}}$ dimeric structures. (Bottom) $\mathrm{Mg}^{1}-\mathrm{Cl}$ (blue) and $\mathrm{Mg}^{2}-\mathrm{Cl}$ (red) distance distributions in $\mathrm{D}_{12}^{\mathrm{ClCl}}$. $\mathrm{Mg}-\mathrm{Cl}$ bond cleavage is observed when the $\mathrm{Mg}-\mathrm{Cl}$ distance is larger than $3.7 \AA$.

Strikingly, $\mathrm{Mg}-\mathrm{Cl}$ bond cleavage was observed only in the asymmetric $\mathbf{D}_{12}^{\mathrm{ClCl}}$ structure with statistically significant probability of finding $\mathrm{Mg}-\mathrm{Cl}$ distances with longer values than $3.7 \AA$, as shown in the inset of Figure 5 top. On the contrary, both the $\mathrm{Mg}-\mathrm{Cl}$ bond length distributions of the least and the most solvated $\mathbf{D}_{11}^{\mathrm{ClCl}}$ and $\mathbf{D}_{22}^{\mathrm{ClCl}}$ species vanish above $3.7 \AA$, indicating statistical irrelevance of $\mathrm{Mg}-\mathrm{Cl}$ bond-cleaved structures. Analysis of the AIMD trajectory evidenced that in all cases the cleavage of the $\mathrm{Mg}-\mathrm{Cl}$ bond occurs between the pentacoordinated $\mathrm{Mg}^{2}$ and the $\mathrm{Cl}_{\mathrm{ax}}$ bridged atom in axial position in the trigonal bipypramid, as shown in Figure 5 bottom. The presence in thermal samples of the monochloride bridged, unsymmetrically solvated structures appears to be an essential ingredient in ligand exchange at each $\mathrm{Mg}$.

Activation of the $\mathrm{Mg}-\mathrm{Cl}$ bond in the axial position is also consistent with $\mathrm{NBO}$ analysis of $\mathrm{D}^{\mathrm{ClCl}}$, which shows that the pentacoordinated $\mathrm{Mg}$ atoms in both $\mathrm{D}_{12}^{\mathrm{ClCl}}$ and $\mathrm{D}_{22}^{\mathrm{ClCl}}$ receive the smallest electron donation from $\mathrm{Cl}\left(\chi^{\mathrm{Mg}} \approx 6 \%\right)$. In particular, 
the bridging chloride, axially coordinated to $\mathrm{Mg}^{2}, \mathrm{Cl}_{\mathrm{ax}}$, has the lowest contribution to this magnesium $\left(\chi^{\mathrm{Mg}} \approx 2 \%\right)$. Such a small donation implies an overpolarization of the $\mathrm{Cl}_{\mathrm{ax}}-\mathrm{Mg}^{2}$ bond, which in turn facilitates opening of the dichloride bridged moiety of $\mathbf{D}_{12}^{\mathrm{ClCl}}$, as observed during AIMD. The asymmetry in the donation between the axial and the equatorial $\mathrm{Cl}$ explains also the selective opening of the ring at the $\mathrm{Cl}_{\mathrm{ax}}-\mathrm{Mg}^{2}$ bond.

The trigonal-bipyramidal geometry on $\mathrm{Mg}^{2}$ in $\mathrm{D}_{12}^{\mathrm{ClCl}}$ was not found in $\mathbf{D}_{22}^{\mathrm{ClCl}}$. Instead, the coordination geometry of $\mathrm{Mg}$ atoms took a distorted square-pyramidal geometry, with an apical THF, and equatorial $\mathrm{Cl}$ atoms, a methyl group, and the remaining THF. In all $\mathbf{D}_{11}^{\mathrm{ClCl}}, \mathbf{D}_{12}^{\mathrm{ClCl}}$, and $\mathbf{D}_{22}^{\mathrm{ClCl}}$, the equilibrium values for the $\mathrm{Cl}-\mathrm{Mg}-\mathrm{Cl}$ bond angle are close to $90^{\circ}$ (Table 1 ), even though the coordination geometries of the $\mathrm{Mg}$ atoms

Table 1. Average Angles $\left(\alpha^{\mathrm{dyn}}, \beta_{1}{ }^{\mathrm{dyn}}\right.$, and $\beta_{2}{ }^{\mathrm{dyn}}$, in degrees) with Associated Standard Deviation (in parentheses) Obtained from Cluster Analysis of the Metadynamics Trajectory and Angles from DFT Optimization with Implicit Solvent $\left(\alpha^{\text {st }}, \beta_{1}^{\text {st }}\right.$, and $\beta_{2}^{\text {st }}$, in degrees $)$

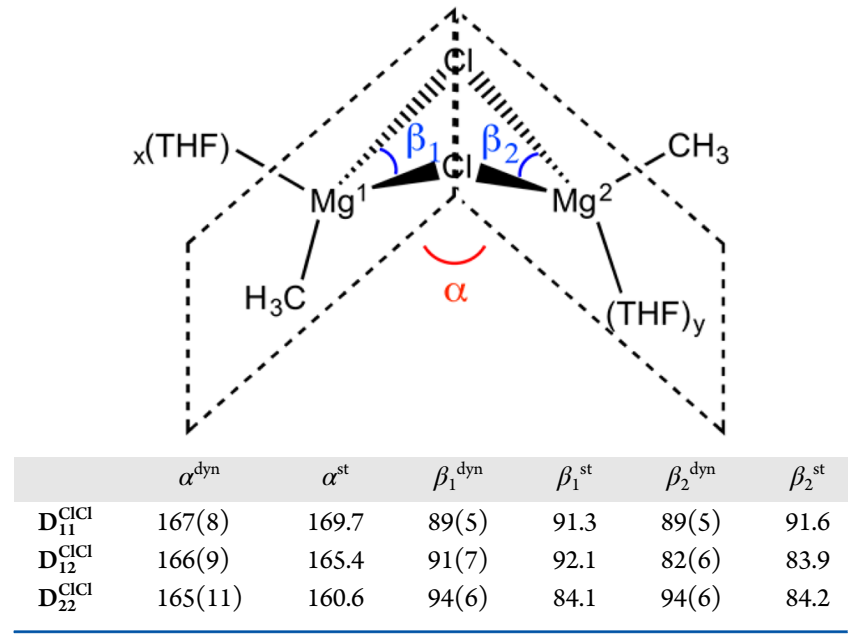

in the structures are different from each other. As an additional structural feature, it is observed that during AIMD simulations the four atoms of the $\mathrm{Mg}(\mu-\mathrm{Cl})_{2} \mathrm{Mg}$ moiety do not lie in the same plane. The average angles between the two $\mathrm{MgCl}_{2}$ planes are reported in Table 1 .

DFT optimization of $\mathbf{D}_{11}^{\mathrm{ClCl}}, \mathbf{D}_{12}^{\mathrm{ClCl}}$, and $\mathbf{D}_{22}^{\mathrm{ClCl}}$ confirmed that the minima on the FES correspond to minima on the PES. However, structural discrepancies are obtained for the species with the largest number of THF molecules in the coordination sphere of the $\mathrm{Mg}$ centers. Thus, the $\mathrm{Mg}$ centers in $\mathbf{D}_{22}^{\mathrm{ClCl}}$ are trigonal-bipyramidal on the PES, while they are distorted square-pyramidal on the FES. This indicates that the solvent cage has an increasing influence on the structure and dynamics of the more flexible, solvated species. AIMD simulations also revealed the existence of interchange of THF molecules in the $\mathrm{Mg}$ solvation shell of $\mathbf{D}_{22}^{\mathrm{ClCl}}$ taking place through an associative mechanism. In this case, a short-lived octahedral structure was formed. The statistical abundance of these structures is however marginal.

Solvation of Methyl Chloride Bridged Structures. The accessible solvation states of the $\mathbf{D}^{\mathrm{ClMe}}$ species in $\mathbf{C}$ and $\mathbf{D}$ wells (Figure 3) were analyzed by metadynamics simulations using the coordination number of the oxygen atoms of THF to each of the $\mathrm{Mg}$ atoms as CVs (Figure 6). Three low-energy solvation structures were obtained. The lowest in energy, $\mathbf{D}_{11}^{\mathrm{ClMe}}$, has two

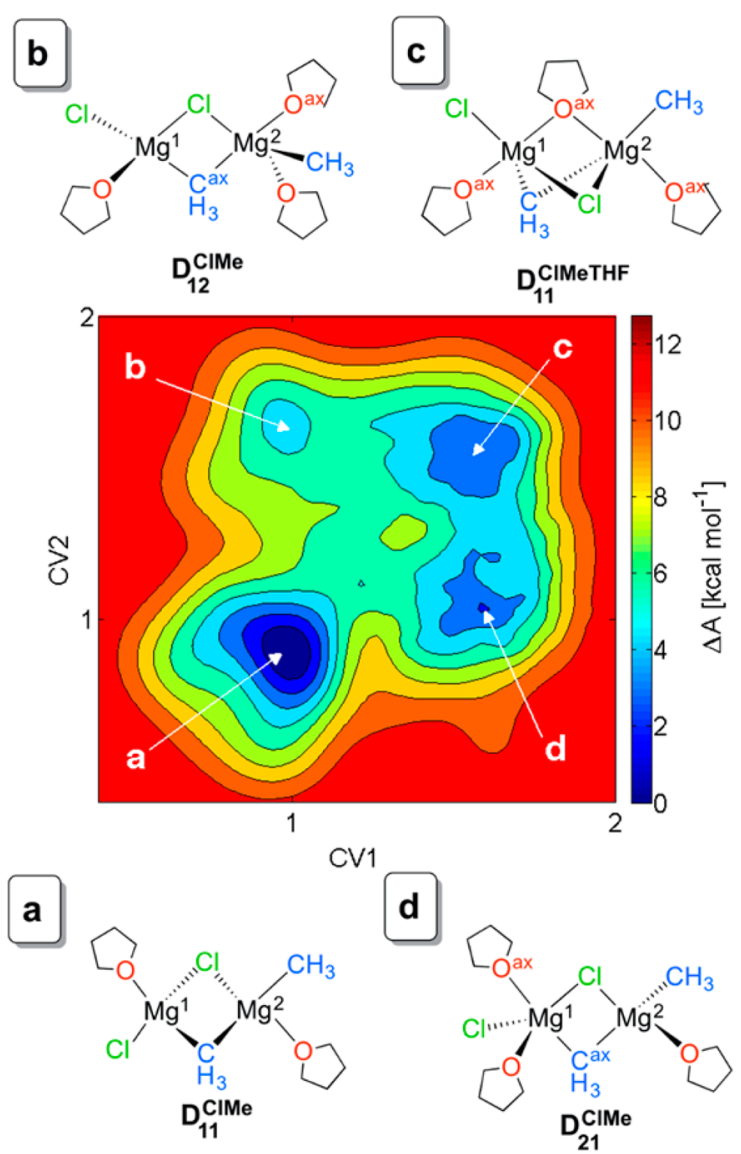

Figure 6. FES for the methyl bridged dimer $\mathbf{D}^{\mathrm{ClMe}}$ equilibria using the THF coordination number to $\mathrm{Mg}^{1}$ (CV1) and the THF coordination number to $\mathrm{Mg}^{2}$ (CV2) as variables, together with the most representative species obtained for wells $\mathbf{a}-\mathbf{d}$.

tetrahedral-coordinated $\mathrm{Mg}$ centers bridged by a $\mathrm{Cl}$ atom and a methyl group (Figure 6a). This structure is favored over the other ones (Figure $6 \mathrm{~b}-\mathrm{d}$ ) by about $3 \mathrm{kcal} \mathrm{mol}^{-1}$. The two other major structures are dinuclear species with three coordinated solvent molecules, $\mathbf{D}_{21}^{\mathrm{ClMe}}$ and $\mathbf{D}_{11}^{\mathrm{ClMeTHF}}$. In the former species, the additional THF is bound to the $\mathrm{Mg}-\mathrm{Cl}$ moiety, while in the latter, THF bridges the two $\mathrm{Mg}$ centers (Figure 6). The free energies of triply bridged species $D_{11}^{\text {ClMeTHF }}$ and the asymmetrically solvated $\mathrm{D}_{21}^{\mathrm{ClMe}}$ differ by only $0.5 \mathrm{kcal}$ $\mathrm{mol}^{-1}$, separated by a barrier on the order of $2 k T$. A well corresponding to the asymmetric structure with two THF molecules coordinated to the $\mathrm{Mg}-\mathrm{CH}_{3}$ moiety $\left(\mathrm{D}_{12}^{\mathrm{ClMe}}\right)$ was also obtained about $5 \mathrm{kcal} \mathrm{mol}^{-1}$ above $\mathbf{D}_{11}^{\mathrm{ClMe}}$ Overall, fast interchange between $D_{21}^{\text {ClMe }}, D_{11}^{\text {ClMeTHF}}$, and $D_{12}^{\text {ClMe }}$ is observed with low activation energy barriers of around $4 \mathrm{kcal} \mathrm{mol}^{-1}$.

All $\mathbf{D}^{\mathrm{ClMe}}$ structures show tetrahedral and trigonalbipyramidal geometries for the $\mathrm{Mg}$ centers solvated by one and two THF molecules, respectively. The bridging methyl ( $\mu$ $\mathrm{CH}_{3}$ ) interacts differently with the two $\mathrm{Mg}$ atoms in the $\mathrm{ClMg}\left(\mu-\mathrm{CH}_{3}\right)(\mu-\mathrm{Cl}) \mathrm{MgCH}_{3}$ dimer. This is due to the asymmetric distribution of the ligands at the two $\mathrm{Mg}$ atoms because $\mathrm{Mg}^{1}$ has a terminal chloride while $\mathrm{Mg}^{2}$ has a terminal methyl group. Moreover, the two $\mathrm{Mg}$ atoms can have different solvation states at room temperature, as shown by the FES in Figure 6. In order to quantify the way the bridging $\mathrm{CH}_{3}$ group interacts with the two $\mathrm{Mg}$ centers in the different structures, the direction of the bridging $\mathrm{p}_{z}$ orbital axis relative to the two C$\mathrm{Mg}$ directions was monitored (Figure 7). 


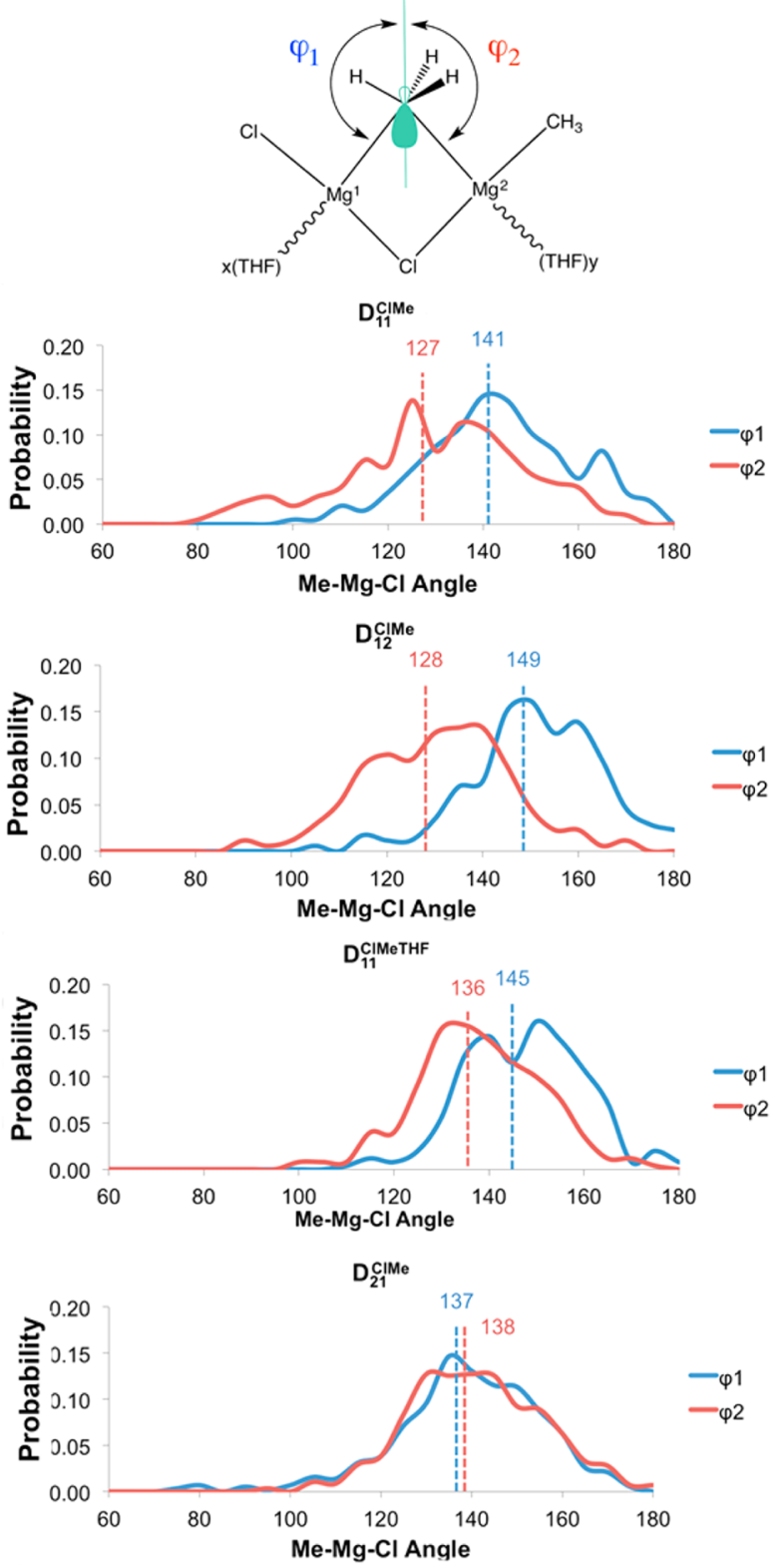

Figure 7. Orientation of the methyl group in $\mathrm{D}^{\mathrm{ClMe}}$ as a function of the solvation state, represented by $\varphi_{1}$ and $\varphi_{2}$. A larger $\varphi$ angle is indicative of a stronger $\mathrm{Mg}-\mathrm{CH}_{3}$ interaction.

In both $\mathrm{D}_{11}^{\mathrm{ClMe}}$ and $\mathrm{D}_{12}^{\mathrm{ClMe}}$, the $\mathrm{p}_{z}$ orbital is oriented toward the $\mathrm{Mg}^{1}-\mathrm{Cl}$ moiety, with average angles $\varphi_{1}$ of approximately 141 and $149^{\circ}$, respectively. In these two structures, $\varphi_{2}$ has average values of 127 and $128^{\circ}$, indicating a poorer interaction of the bridging methyl with the $\mathrm{Mg}^{2} \mathrm{p}_{z}$ orbital. In $\mathbf{D}_{11}^{\mathrm{CIMeTHF}}$, the $\mu$ $\mathrm{CH}_{3}$ bridging group is more equally shared between the two $\mathrm{Mg}$ centers, as indicated by the values of $\varphi_{1}$ and $\varphi_{2}$ that oscillate around 145 and $136^{\circ}$, respectively. A larger solvation for the $\mathrm{Mg}$ bound to the terminal $\mathrm{Cl}$ than the other $\mathrm{Mg}$ atom $\left(\mathbf{D}_{21}^{\mathrm{CIMe}}\right)$ results in practically equal sharing of the bridging methyl between the two $\mathrm{Mg}$ centers. In this case, both angles $\varphi_{1}$ and $\varphi_{2}$ oscillate around an average value of $\sim 137^{\circ}$.

The orientation of the bridging methyl group is thus highly sensitive to the chemical groups and the solvation at each $\mathrm{Mg}$ center. For equal solvation, the methyl interacts more with the more electron deficient $\mathrm{Mg}^{1}$ center, that is, the one with the terminal chloride. Increasing solvation of $\mathrm{Mg}^{1}$ by either bridging or terminal THF results in an increased interaction of the bridging methyl group with $\mathrm{Mg}^{2}$ bearing the terminal methyl group. In this way, the solvent helps the bridging methyl group weaken its interaction with $\mathrm{Mg}^{1}$ and increase that to $\mathrm{Mg}^{2}$, assisting the transformation of $\mathrm{CH}_{3} \mathrm{MgCl}$ into $\mathrm{MgCl}_{2}$ and $\operatorname{Mg}\left(\mathrm{CH}_{3}\right)_{2}$.

Geometry optimizations on the PES with DFT methods of the minima $\mathbf{D}_{11}^{\text {ClMe }}, \mathbf{D}_{12}^{\text {ClMe }}, \mathbf{D}_{11}^{\text {CIMeTHF }}$, and $\mathbf{D}_{21}^{\text {ClMe }}$ on the FES gave minima with similar structures, as indicated in Table 2 . In all

Table 2. Average angles $\left(\alpha^{\mathrm{dyn}}, \beta_{1}{ }^{\mathrm{dyn}}\right.$, and $\beta_{2}^{\text {dyn }}$, in degrees) with the Standard Deviations (in parentheses) Obtained from Cluster Analysis of the Metadynamics Trajectory and Optimized Angles from DFT Calculations with Implicit Solvent $\left(\alpha^{\text {st }}, \beta_{1}{ }^{\text {st }}\right.$, and $\beta_{2}{ }^{\text {st }}$, in degrees $)$

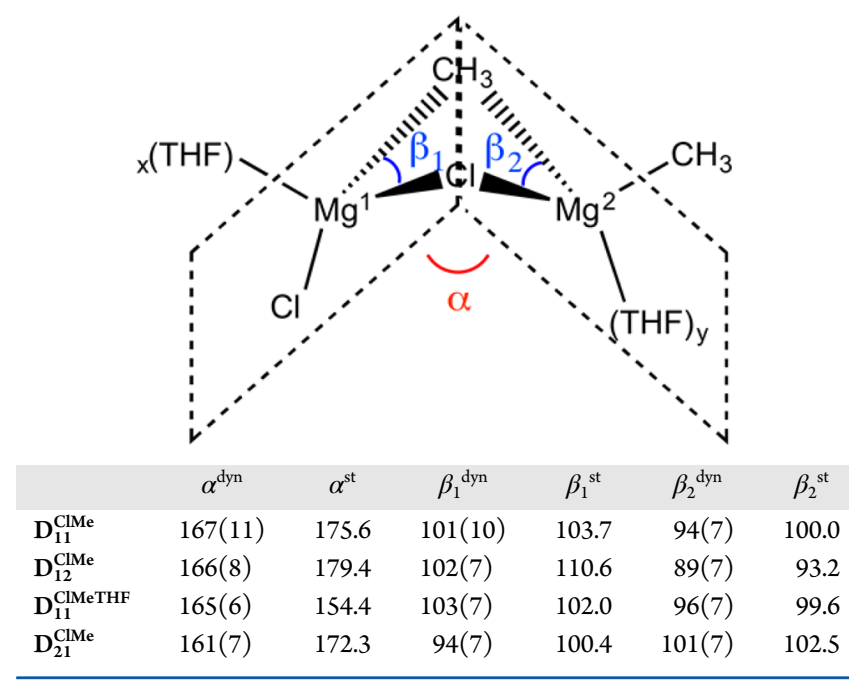

cases, trigonal-bipyramid geometries were found on the pentacoordinated $\mathrm{Mg}$ atoms with the bridging $\mathrm{CH}_{3}$ and a terminal THF in the axial positions. NBO analysis on the optimized structures showed slightly higher electron donation of the bridged $\mathrm{CH}_{3}$ lone pair to the $\mathrm{Mg}$ of the $\mathrm{Mg}-\mathrm{Cl}$ moiety $\left(\chi^{\mathrm{Mg} 1}=5.7,5.2\right.$, and $\left.4.6 \%\right)$ compared to that for the $\mathrm{Mg}-\mathrm{CH}_{3}$ moiety $\left(\chi^{\mathrm{Mg} 2}=3.7,3.8\right.$, and $\left.3.6 \%\right)$ for $\mathbf{D}_{11}^{\mathrm{ClMe}}, \mathrm{D}_{12}^{\mathrm{ClMe}}$, and $\mathrm{D}_{11}^{\text {ClMeTHF }}$, respectively. With increasing solvation of $\mathrm{Mg}^{1}$, as in $\mathrm{D}_{21}^{\mathrm{ClMe}}$, donation of the bridging methyl group to the two $\mathrm{Mg}$ centers becomes equivalent $\left(\chi^{\mathrm{Mg} 1}=4.3 \% ; \chi^{\mathrm{Mg} 2}=4.2 \%\right)$, consistent with the distribution of the $\varphi_{1}$ and $\varphi_{2}$ angles during AIMD simulations (Figure 8). Although small, the increased electron donation of the Me group to $\mathrm{Mg}^{2}$, which already bears the other methyl group, is in agreement with $D_{21}^{\text {ClMe }}$ being the most prone of the methyl chloride bridged dimers to yield the final products $\mathrm{MgCl}_{2}$ and $\mathrm{Mg}\left(\mathrm{CH}_{3}\right)_{2}$.

Reaction Pathway of the Schlenk Equilibrium. The computational results presented above allow reconstruction of the full reaction pathway of the Schlenk equilibrium in a THF solution. Figure 8 presents the set of structures, localized as minima on the FES, that are involved in the transformation of the reactants $\mathrm{CH}_{3} \mathrm{MgCl}(\mathrm{THF})_{2}$ to the products $\mathrm{Mg}$ $\left(\mathrm{CH}_{3}\right)_{2}(\mathrm{THF})_{2}$ and $\mathrm{MgCl}_{2}(\mathrm{THF})_{n}(n=2-4)$. The scheme also highlights the key role played by the solvent in assisting the $\mathrm{Cl} / \mathrm{CH}_{3}$ ligand exchange.

The Schlenk equilibrium starts by dimerization of $\left(\mathrm{CH}_{3}\right)$ $\mathrm{MgCl}(\mathrm{THF})_{2}$ via the two chlorides to form the dichloride bridged species $\mathbf{D}_{22}^{\mathrm{ClCl}}$. Static calculations show that this reaction 


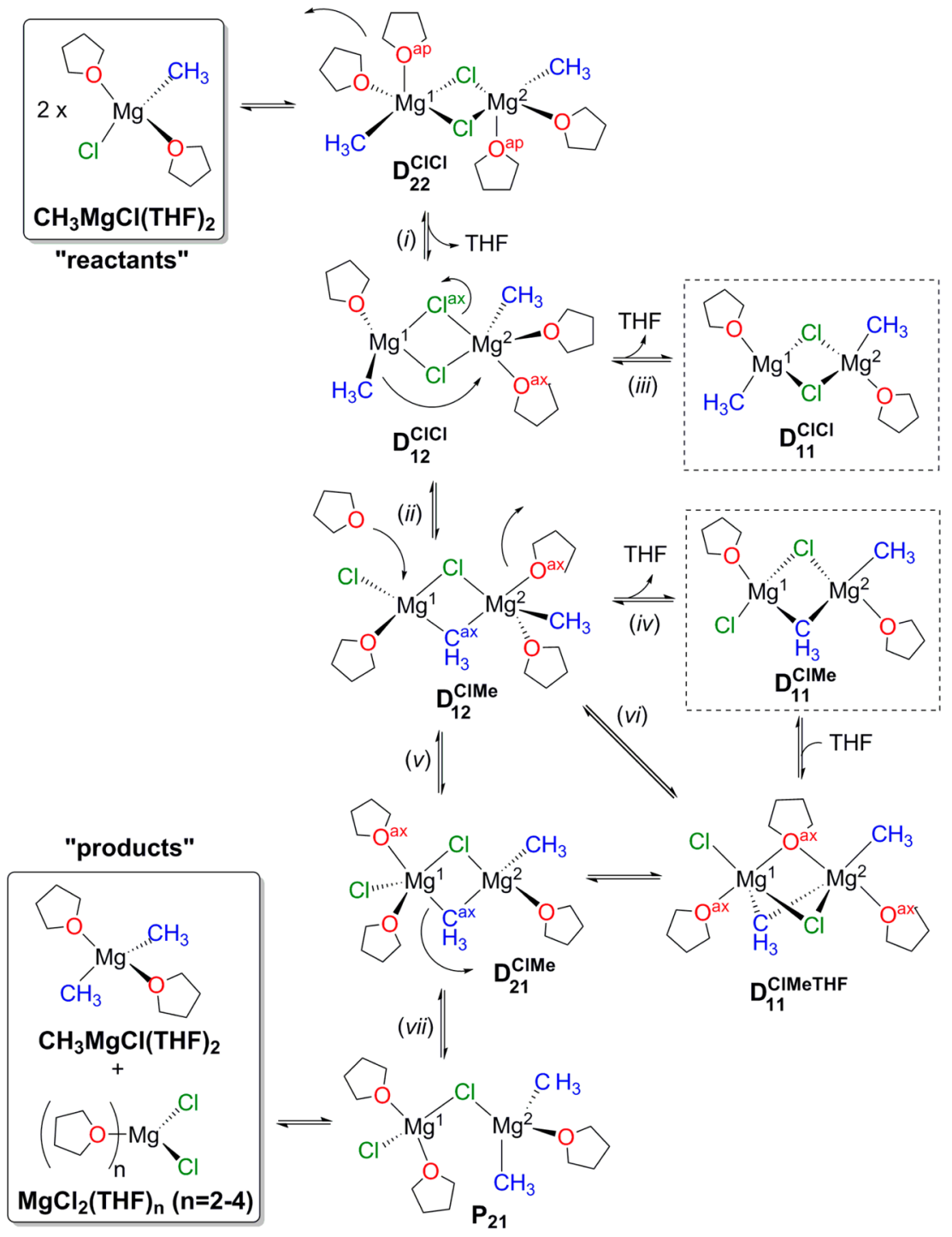

Figure 8. Intermediates involved in the Schlenk equilibrium according to dynamic simulations. Arrows indicate the chemical transformations along the main pathway leading from monomeric reactants to products (inside of solid squares). The most stable dichloride and methyl chloride bridged dinuclear species are inside of dashed squares.

is slightly endoergic by $4.9 \mathrm{kcal} \mathrm{mol}{ }^{-1}$, consistent with experimental results. ${ }^{22,76}$

The coordination geometry of the pentacoordinated $\mathrm{Mg}$ atoms in $\mathbf{D}_{22}^{\mathrm{ClCl}}$ was found to be distorted square-pyramidal when exploring the FES but trigonal-bipyramidal when performing $a b$ initio geometry optimizations on the PES. Such discrepancy evidences a strong influence of the surrounding solvent molecules on the structural geometry of $\mathbf{D}_{22}^{\mathrm{ClCl}}$. THF exchange on the $\mathrm{Mg}$ atom may occur through addition of one THF to form an octahedral species. ${ }^{77-79}$ These last transient structures are very short lived and thus have not been included in Figure 8 .

Desolvation of $\mathbf{D}_{22}^{\mathrm{ClCl}}$ by one THF molecule yields an asymmetrical dinuclear complex $\left(\mathbf{D}_{12}^{\mathrm{ClCl}}\right)$ with tetrahedral and pyramidal-trigonal geometries for $\mathrm{Mg}^{1}$ and $\mathrm{Mg}^{2}$, respectively. This trisolvated species can lose one THF molecule to produce the disolvated $\left(\mathbf{D}_{11}^{\mathrm{ClCl}}\right)$, which was found to be the most stable species in solution. Tetrahedral coordination of $\mathrm{Mg}$ is also the one preferred in the solid state, as shown by reported crystallographic structures of related $\mathrm{Mg}_{2} \mathrm{X}_{2} \mathrm{R}_{2}$ species. ${ }^{28,80}$ The difference in energy between $\mathrm{D}_{11}^{\mathrm{ClCl}}$ and the least stable intermediate $\mathrm{D}_{12}^{\mathrm{ClCl}}$ is $2.7 \mathrm{kcal} / \mathrm{mol}^{-1}$ with an activation energy barrier of less than $5 \mathrm{kcal} \mathrm{mol}^{-1}$ (Figure 4). Therefore, all $\mathbf{D}_{11}^{\mathrm{ClCl}}$, $\mathbf{D}_{12}^{\mathrm{ClCl}}$, and $\mathbf{D}_{22}^{\mathrm{ClCl}}$ species are expected to coexist and undergo interconversion at room temperature.

Interestingly, not all species favor the $\mathrm{Mg}-\mathrm{Cl}$ bond cleavage required for the $\mathrm{Cl} / \mathrm{Me}$ ligand exchange. Analysis of the $\mathrm{Mg}-\mathrm{Cl}$ bond distances in $\mathbf{D}_{11}^{\mathrm{ClCl}}, \mathbf{D}_{22}^{\mathrm{ClCl}}$, and $\mathbf{D}_{12}^{\mathrm{ClCl}}$ (Figure 5 top) shows that the formation of monochloride bridged species takes place preferentially from $\mathbf{D}_{12}^{\mathrm{ClCl}}$. NBO analysis indicates that asymmetric solvation of $\mathbf{D}_{12}^{\mathrm{ClCl}}$ favors $\mathrm{Mg}^{2}-\mathrm{Cl}^{\text {ax }}$ bond cleavage (step (ii) in Figure 8). In this complex, the higher solvation on $\mathrm{Mg}^{2}$ weakens the $\mathrm{Mg}^{2}-\mathrm{Cl}$ bond, while the lower solvation on $\mathrm{Mg}^{1}$ makes it prone to accept an extra anionic ligand during the $\mathrm{Cl} / \mathrm{CH}_{3}$ exchange process. Analysis on several trajectories, such as the one represented in Figure 9, reaffirms that the chloride involved in the cleavage is the one located in the axial position of $\mathrm{Mg}^{2}$ (Figure 5 bottom). The monobridged species generated by $\mathrm{Mg}-\mathrm{Cl}$ bond cleavage (snapshot 2 in Figure 9) is short-lived and rapidly evolves into methyl chloride bridged structures $\left(\mathrm{D}^{\mathrm{ClMe}}\right)$. The methyl group occupying the bridging position comes from $\mathrm{Mg}^{1}$, as shown in snapshot 3; this is consistent with 


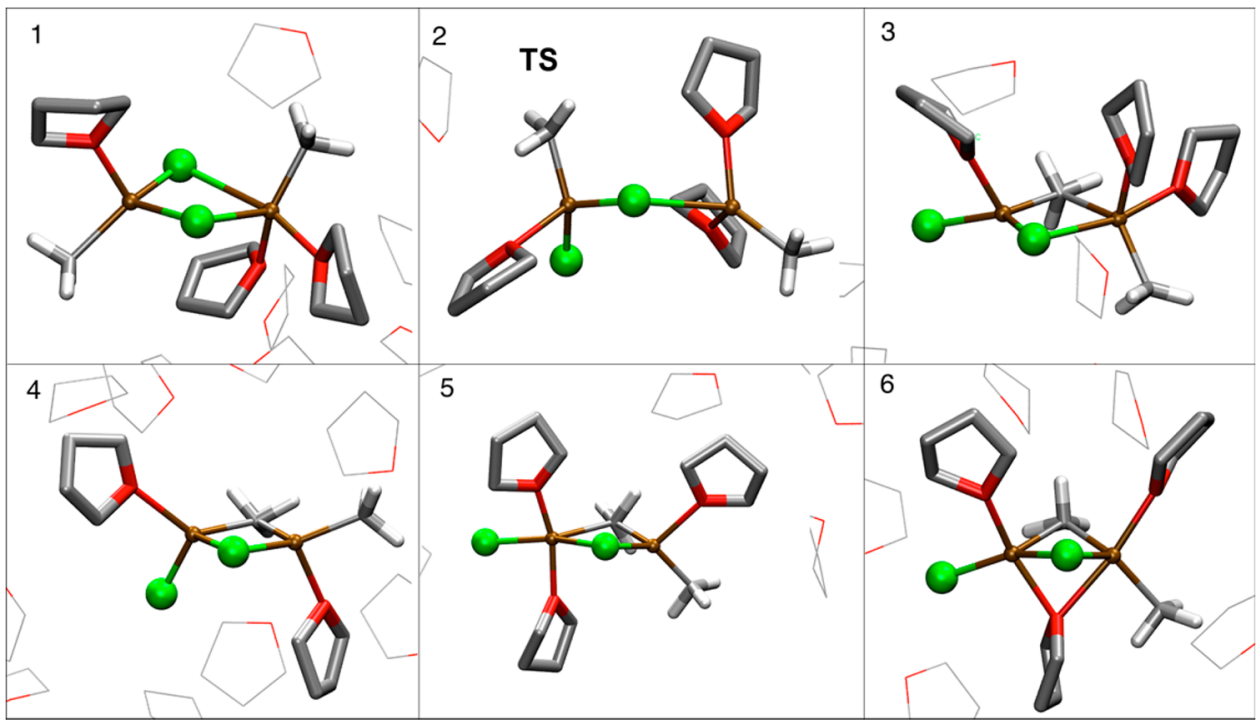

Figure 9. Snapshots for the methyl transfer reaction in $\mathbf{D}_{12}^{\mathrm{ClCl}}\left(\mathrm{Mg}^{1}\right.$ on the left-hand side and $\mathrm{Mg}^{2}$ on the right for all snapshots): (1) initial $\mathbf{D}_{12}^{\mathrm{ClCl}}$ structure, (2) transition state of the transmetalation reaction, (3) $\mathbf{D}_{12}^{\text {ClMe }},(4)$ solvent loss to form $\mathbf{D}_{11}^{\text {ClMe }}$, and (5) solvent addition to form $\mathbf{D}_{21}^{\mathrm{ClMe}}$ and (6) $\mathrm{D}_{11}^{\text {ClMeTHF}}$. The atoms for the Grignard reagent and the coordinating THF molecules are depicted as balls and/or sticks and colored according to standard color codes. Selected neighboring solvent molecules are drawn with thin lines.

the higher electron density on the $\mathrm{MgCl}(\mathrm{THF})(\mu-\mathrm{Cl})$ fragment compared to that on $\mathrm{Mg}(\mathrm{THF})_{2}(\mu-\mathrm{Cl})$ calculated for the structure shown in snapshot 2.

The first $\mathbf{D}^{\mathrm{ClMe}}$ species generated after $\mathrm{Mg}-\mathrm{Cl}$ bond cleavage is the $\mathbf{D}_{12}^{\mathrm{ClMe}}$ complex (snapshot 3 in Figure 9). This species is however the least stable of the four solvation states observed by AIMD, with a free energy difference of $+5 \mathrm{kcal} \mathrm{mol}^{-1}$ (Figure 4) over the most stable solvation structure. As in the case of $\mathbf{D}^{\mathrm{ClCl}}$ species, the most stable $\mathbf{D}^{\mathrm{ClMe}}$ complex is the disolvated $\mathrm{D}_{11}^{\mathrm{ClMe}}$, in which both $\mathrm{Mg}$ atoms have tetrahedral coordination geometry. However, $\mathbf{D}^{\text {ClMe }}$ incorporates other trisolvated species, $D_{11}^{\text {ClMeTHF }}$ and $D_{21}^{\text {ClMe }}$, which are both $3 \mathrm{kcal} \mathrm{mol}^{-1}$ above $\mathbf{D}_{11}^{\text {ClMe }}$. Exchange between these species has low activation energy barriers (smaller than $4 \mathrm{kcal} \mathrm{mol}^{-1}$ ) and involves the addition of an external THF either at the bridging position $\left(\mathbf{D}_{11}^{\mathrm{ClMe}} \rightarrow \mathbf{D}_{11}^{\mathrm{ClMeTHF}}\right)$ or at the terminal position of $\mathrm{Mg}^{1}\left(\mathbf{D}_{11}^{\mathrm{CIMe}} \rightarrow \mathbf{D}_{21}^{\mathrm{ClMe}}\right)$. Internal rearrangement of THF from bridging to terminal is also observed $\left(\mathrm{D}_{11}^{\mathrm{ClMeTHF}} \rightarrow \mathrm{D}_{21}^{\mathrm{ClMe}}\right)$ with an even lower energy barrier $\left(<0.5 \mathrm{kcal} \mathrm{mol}^{-1}\right)$. The higher stability of $\mathbf{D}_{21}^{\mathrm{ClMe}}$ compared to that of $\mathrm{D}_{12}^{\mathrm{ClMe}}$ is consistent with the higher solvation of the most electrophilic $\mathrm{Mg}$ atom $\left(\mathrm{Mg}^{1}\right)$, that is, the one with a terminal chloride.

In order to form the final products, both $\mathrm{Mg}^{2}-\mathrm{Cl}$ and $\mathrm{Mg}^{1}-$ $\mathrm{CH}_{3}$ bonds need to be cleaved. This however does not take place simultaneously but consecutively, and solvation plays an important role. Because $\mathrm{Cl}$ is a much better ligand than $\mathrm{CH}_{3}{ }^{28}$ the $\mathrm{Mg}-\mathrm{CH}_{3}$ bond is the first to be broken. Analysis of the orientation of the formal lone pair in the bridging methyl ligand shows that at equal solvation of $\mathrm{Mg}$ atoms in $\mathrm{D}^{\mathrm{ClMe}}, \mu-\mathrm{CH}_{3}$ is more strongly bonded to $\mathrm{Mg}^{1}$ than to $\mathrm{Mg}^{2}$ because $\mathrm{Mg}^{1}$ is more electrophilic (Figure 7). This preference is however modified by increasing the solvation of $\mathrm{Mg}^{1}$ relative to $\mathrm{Mg}^{2}$. Thus, in $\mathbf{D}_{21}^{\mathrm{ClMe}}$, the methyl is equally bonded to $\mathrm{Mg}^{1}$ and $\mathrm{Mg}^{2}$. In addition, in this species, the axial position occupied by the bridged methyl group in the coordination sphere of $\mathrm{Mg}^{1}$ also favors the $\mathrm{Mg}^{1}-\mathrm{C}^{\mathrm{ax}} \mathrm{H}_{3}$ bond cleavage. An increase in solvation of $\mathrm{Mg}^{1}$ thus yields the preproduct of the Schlenk equilibrium $\left(\mathbf{P}_{21}\right.$ and minimum $\mathbf{E}$ in Figure 3$)$, consisting of a $\mathrm{Mg}^{1} \mathrm{Cl}_{2}$ species bridged by way of a single chloride to $\mathrm{Mg}^{2}\left(\mathrm{CH}_{3}\right)_{2}$. An increase in solvation of both $\mathrm{Mg}$ centers is expected to favor the final release of the mononuclear $\mathrm{MgCl}_{2}$ and $\mathrm{Mg}\left(\mathrm{CH}_{3}\right)_{2}$ products. The dissociation energy from $\mathbf{P}_{21}$ to $\mathrm{CH}_{3} \mathrm{MgCl}$ $(\mathrm{THF})_{2}$ and the most stable $\mathrm{MgCl}_{2}(\mathrm{THF})_{3}$ has been estimated to be $-8.7 \mathrm{kcal} \mathrm{mol}^{-1}$ in this study (see Figure S4 for further details).

Despite their relatively low abundance in solution, as also experimentally observed, ${ }^{22}$ formation of dimeric adducts is key to the evolution of the Schlenk equilibrium reaction. The reaction pathway identified in this study highlights the crucial role of the solvent in assisting $\mathrm{Cl} / \mathrm{Me}$ exchange in the Schlenk equilibrium. Most importantly, it shows that the tetracoordinated $\mathrm{Mg}$ species proposed in most computational studies $^{28,81,82}$ are indeed the most stable structures but are not on the reactive pathway. Instead, asymmetric solvation on $\mathrm{Mg}$ atoms is needed to promote the $\mathrm{Mg}-\mathrm{Cl}$ and $\mathrm{Mg}-\mathrm{CH}_{3}$ bond cleavage to go from $\mathrm{MgCH}{ }_{3} \mathrm{Cl}$ to $\mathrm{Mg}\left(\mathrm{CH}_{3}\right)_{2}$ and $\mathrm{MgCl}_{2}$. These tetra/pentacoordinated $\mathrm{Mg}$ dimers $\left(\mathbf{D}_{12}^{\mathrm{ClCl}}\right.$ and $\mathbf{D}_{21}^{\mathrm{ClMe}}$ ) are transient intermediates that interchange with the most stable solvation structures at room temperature. In addition, the bridging ligand involved in the bond-breaking process is located always in the axial position of the pentacoordinated $\mathrm{Mg}$ atom. This detailed information on the Schlenk equilibrium mechanism will be useful for a better understanding of the reactivity of the Grignard reagents. In addition, this study may help to better understand other transmetalation processes, such as those involved in the Kumada and Negishi cross-coupling reactions, ${ }^{4,83-86}$ which are also assisted by solvent.

\section{CONCLUSIONS}

The here presented AIMD study of the Schlenk equilibrium reaction, in which two molecules of $\mathrm{CH}_{3} \mathrm{MgCl}$ exchange methyl and chloride groups to yield $\mathrm{Mg}\left(\mathrm{CH}_{3}\right)_{2}$ and $\mathrm{MgCl}_{2}$, showed how the ether solvent (THF here) has a crucial role in assisting the reaction. Although coordination of the solvent is needed for stabilizing the various mono- and dinuclear $\mathrm{Mg}$ complexes, the stabilizing effect is not the only factor at work. 
The reaction goes via the formation of a dinuclear $\left(\mathrm{CH}_{3}\right) \mathrm{Mg}(\mu-\mathrm{Cl})_{2} \mathrm{Mg}\left(\mathrm{CH}_{3}\right)$ intermediate whose most stable solvated form (with a single THF at each $\mathrm{Mg}$ ) is unreactive. The chloride/methyl exchange is promoted by making the two $\mathrm{Mg}$ atoms electronically different. The calculations show that these differences are created by different solvations of the two $\mathrm{Mg}$ centers. The cleavage of the $\mathrm{Mg}-\mathrm{Cl}$ bond and associated shift of the methyl group from the terminal to bridging position is assisted by increasing the solvation at the $\mathrm{Mg}$ involved in the bond cleavage while keeping the other $\mathrm{Mg}$ less solvated.

A similar process occurs at the dinuclear $\left(\mathrm{CH}_{3}\right) \mathrm{Mg}(\mu$ $\left.\mathrm{CH}_{3}\right)(\mu-\mathrm{Cl}) \mathrm{MgCl}$; the cleavage of the bond between $\mathrm{Mg}$ and the bridging $\mathrm{CH}_{3}$ group to form solvated $\mathrm{Mg}\left(\mathrm{CH}_{3}\right)_{2}$ and $\mathrm{MgCl}_{2}$ requires the chloride-rich $\mathrm{Mg}$ atom to be more solvated than the methyl-rich $\mathrm{Mg}$ one. Increasing solvation at one $\mathrm{Mg}$ favors bond cleavage, while decreasing solvation on the other one favors the formation of new terminal bonds.

The species selected by the dynamics to be on the reaction pathway are not necessarily minima on the PES, which emphasizes the need for the former method. Our findings highlight the need of including explicit solvent dynamics in the modeling of such reactions because this is crucial in allowing the $\mathrm{Cl} / \mathrm{CH}_{3}$ group exchange to occur with a low energy barrier.

\section{ASSOCIATED CONTENT}

\section{S Supporting Information}

The Supporting Information is available free of charge on the ACS Publications website at DOI: 10.1021/acs.jpcb.7b02716.

Metadynamics parameters, natural bond orbital analysis, DFT optimized geometries, and solvation properties for different sizes of the simulation box (PDF)

\section{AUTHOR INFORMATION}

\section{Corresponding Authors}

*E-mail: ainara.nova@kjemi.uio.no (A.N.).

*E-mail: michele.cascella@kjemi.uio.no (M.C.).

ORCID ${ }^{\circ}$

Odile Eisenstein: 0000-0001-5056-0311

Notes

The authors declare no competing financial interest.

\section{ACKNOWLEDGMENTS}

This work was supported by the Research Council of Norway (RCN) through the CoE Centre for Theoretical and Computational Chemistry (CTCC) Grant No. 179568/V30 and $171185 /$ V30 and by the Norwegian Supercomputing Program (NOTUR) (Grant No. NN4654K). A.N. thanks the RCN for Grants 221801/F20 and 250044/F20. The authors thank Elisa Rebolini for enlightening discussion.

\section{REFERENCES}

(1) Grignard, V. Sur Quelques Nouvelles Combinaisons Organométalliques du Magnésium et Leur Application à des Synthèses d'Alcools et d'Hydrocabures. C. R. Acad. Sci. 1900, 130, 1322-1324.

(2) Grignard, V. The Use of Organomagnesium Compounds in Preparative Organic Chemistry-Nobel Lecture 1912 Nobel Lectures. Chemistry 1921, 1966, 234-246.

(3) Corriu, R. J. P.; Massé, J. P. Activation of Grignard Reagents by Transition-Metal Complexes. A New and Simple Synthesis of TransStilbenes and Polyphenyls. J. Chem. Soc., Chem. Commun. 1972, 144a144a.
(4) Tamao, K.; Sumitani, K.; Kumada, M. Selective Carbon-Carbon Bond Formation by Cross-Coupling of Grignard Reagents with Organic Halides. Catalysis by Nickel-Phosphine Complexes. J. Am. Chem. Soc. 1972, 94, 4374-4376.

(5) Fürstner, A.; Leitner, A.; Méndez, M.; Krause, H. Iron-Catalyzed Cross-Coupling Reactions. J. Am. Chem. Soc. 2002, 124, 13856-13863.

(6) Frisch, A. C.; Beller, M. Catalysts for Cross-Coupling Reactions with Non-activated Alkyl Halides. Angew. Chem., Int. Ed. 2005, 44, 674-688.

(7) Terao, J.; Kato, Y.; Kambe, N. Titanocene-Catalyzed Regioselective Alkylation of Styrenes with Grignard Reagents Using $\beta$-Bromoethyl Ethers, Thioethers, or Amines. Chem. - Asian J. 2008, 3, $1472-1478$.

(8) Vechorkin, O.; Barmaz, D.; Proust, V.; Hu, X. Ni-Catalyzed Sonogashira Coupling of Nonactivated Alkyl Halides: Orthogonal Functionalization of Alkyl Iodides, Bromides, and Chlorides. J. Am. Chem. Soc. 2009, 131, 12078-12079.

(9) Adrio, J.; Carretero, J. C. Functionalized Grignard Reagents in Kumada Cross-Coupling Reactions. ChemCatChem 2010, 2, 13841386.

(10) Jana, R.; Pathak, T. P.; Sigman, M. S. Advances in Transition Metal ( $\mathrm{Pd}, \mathrm{Ni}, \mathrm{Fe})$-Catalyzed Cross-Coupling Reactions Using Alkylorganometallics as Reaction Partners. Chem. Rev. 2011, 111, 14171492.

(11) Cong, X.; Tang, H.; Zeng, X. Regio- and Chemoselective Kumada-Tamao-Corriu Reaction of Aryl Alkyl Ethers Catalyzed by Chromium Under Mild Conditions. J. Am. Chem. Soc. 2015, 137, 14367-14372.

(12) Neufeld, R.; Teuteberg, T. L.; Herbst-Irmer, R.; Mata, R. A.; Stalke, D. Solution Structures of Hauser Base $\mathrm{iPr}_{2} \mathrm{NMgCl}$ and TurboHauser Base $\mathrm{iPr}_{2} \mathrm{NMgCl} \cdot \mathrm{LiCl}$ in THF and the Influence of $\mathrm{LiCl}$ on the Schlenk-Equilibrium. J. Am. Chem. Soc. 2016, 138, 4796-4806.

(13) Seyferth, D. The grignard reagents. Organometallics 2009, 28, $1598-1605$.

(14) Guggenberger, L. J.; Rundle, R. E. Crystal Structure of the Ethyl Grignard Reagent, Ethylmagnesium Bromide Dietherate. J. Am. Chem. Soc. 1968, 90, 5375-5378.

(15) Vallino, M. Structure Cristalline de $\mathrm{CH}_{3} \mathrm{MgBr} \cdot 3 \quad \mathrm{C}_{4} \mathrm{H}_{8} \mathrm{O}$. J. Organomet. Chem. 1969, 20, 1-10.

(16) Toney, J.; Stucky, G. D. The Stereochemistry of Polynuclear Compounds of the Main Group Elements $\left[\mathrm{C}_{2} \mathrm{H}_{5} \mathrm{Mg}_{2} \mathrm{Cl}_{3}\left(\mathrm{C}_{4} \mathrm{H}_{8} \mathrm{O}\right)_{3}\right]_{2}$, a Tetrameric Grignard Reagent. J. Organomet. Chem. 1971, 28, 5-20.

(17) Blasberg, F.; Bolte, M.; Wagner, M.; Lerner, H.-W. An Approach to Pin Down the Solid-State Structure of the "Turbo Grignard. Organometallics 2012, 31, 1001-1005.

(18) Smith, M. B.; Becker, W. E. The constitution of the grignard reagent-III:The reaction between $\mathrm{R}_{2} \mathrm{Mg}$ and $\mathrm{MgX}_{2}$ in tetrahydrofuran. Tetrahedron 1967, 23, 4215-4227.

(19) Smith, M. B.; Becker, W. E. The constitution of the Grignard Reagent - I. The reaction between diethyl magnesium and magnesium bromide in diethyl ether. Tetrahedron Lett. 1965, 6, 3843-3847.

(20) Ashby, E. C.; Nackashi, J.; Parris, G. E. Composition of Grignard compounds. X. NMR, IR, and molecular association studies of some methylmagnesium alkoxides in diethyl ether, tetrahydrofuran, and benzene. J. Am. Chem. Soc. 1975, 97, 3162-3171.

(21) Schlenk, W.; Schlenk, W. Über die Konstitution der Grignardschen Magnesiumverbindungen. Ber. Dtsch. Chem. Ges. B 1929, 62, 920-924.

(22) Walker, F. W.; Ashby, E. C. Composition of Grignard compounds. VI. Nature of association in tetrahydrofuran and diethyl ether solutions. J. Am. Chem. Soc. 1969, 91, 3845-3850.

(23) Sobota, P.; Duda, B. Influence of $\mathrm{MgCl}_{2}$ on Grignard Reagent Composition in Tetrahydrofuran. III. J. Organomet. Chem. 1987, 332, 239-245.

(24) Sakamoto, S.; Imamoto, T.; Yamaguchi, K. Constitution of Grignard Reagent $\mathrm{RMgCl}$ in Tetrahydrofuran. Org. Lett. 2001, 3, 1793-1795.

(25) Hohenberg, P.; Kohn, W. Inhomogeneous Electron Gas. Phys. Rev. B 1964, 136, 864-871. 
(26) Kohn, W.; Sham, L. J. Self-Consistent Equations Including Exchange and Correlation Effects. Phys. Rev. A 1965, 140, 1133-1138. (27) Jiménez-Halla, J. O. C.; Bickelhaupt, F. M.; Solà, M. Organomagnesium clusters: Structure, stability, and bonding in archetypal models. J. Organomet. Chem. 2011, 696, 4104-4111.

(28) Lioe, H.; White, J. M.; O’Hair, R. A. J. Preference for bridging versus terminal ligands in magnesium dimers. J. Mol. Model. 2011, 17, $1325-1334$

(29) Henriques, A. M.; Barbosa, A. G. H. Chemical Bonding and the Equilibrium Composition of Grignard Reagents in Ethereal Solutions. J. Phys. Chem. A 2011, 115, 12259-12270.

(30) Ramirez, F.; Sarma, R.; Chaw, F.; McCaffrey, T. M.; et al. Magnesium bromide-tetrahydrofuran complexes: bis(tetrahydrofuran)magnesium bromide, tris(tetrahydrofuran)magnesium bromide, tetrakis(tetrahydrofuran)magnesium bromide, and diaquotetrakis(tetrahydrofuran)magnesium bromide. A reagent for the preparation of anhydrous magnesium phosphodiester salts. J. Am. Chem. Soc. 1977, 99, 5285-5289.

(31) Pirinen, S.; Koshevoy, I. O.; Denifl, P.; Pakkanen, T. T. A Single-Crystal Model for $\mathrm{MgCl}_{2}$ - Electron Donor Support Materials: $\left[\mathrm{Mg}_{3} \mathrm{Cl}_{5}(\mathrm{THF})_{4} \mathrm{Bu}\right]_{2}(\mathrm{Bu}=\mathrm{n}$-Butyl). Organometallics 2013, 32, 42084213 .

(32) Ashby, E. C.; Becker, W. E. Concerning the Structure of the Grignard Reagent. J. Am. Chem. Soc. 1963, 85, 118-119.

(33) Tammiku-Taul, J.; Burk, P.; Tuulmets, A. Theoretical Study of Magnesium Compounds: The Schlenk Equilibrium in the Gas Phase and in the Presence of $\mathrm{Et}_{2} \mathrm{O}$ and THF Molecules. J. Phys. Chem. A 2004, 108, 133-139.

(34) Tobisu, M.; Chatani, N. Cross-Couplings Using Aryl Ethers via $\mathrm{C}-\mathrm{O}$ Bond Activation Enabled by Nickel Catalysts. Acc. Chem. Res. 2015, 48, 1717-1726.

(35) Cahiez, G.; Moyeux, A.; Cossy, J. Grignard Reagents and NonPrecious Metals: Cheap and Eco-Friendly Reagents for Developing Industrial Cross-Couplings. A Personal Account. Adv. Synth. Catal. 2015, 357, 1983-1989.

(36) Tasker, S. Z.; Standley, E. A.; Jamison, T. F. Recent Advances in Homogeneous Nickel Catalysis. Nature 2014, 509, 299-309.

(37) Laio, A.; Parrinello, M. Escaping Free-Energy Minima. Proc. Natl. Acad. Sci. U. S. A. 2002, 99, 12562-12566.

(38) Iannuzzi, M.; Laio, A.; Parrinello, M. Efficient Exploration of Reactive Potential Energy Surfaces Using Car-Parrinello Molecular Dynamics. Phys. Rev. Lett. 2003, 90, 23-26.

(39) Vuilleumier, R.; Sprik, M. Electronic Properties of Hard and Soft Ions in Solution: Aqueous $\mathrm{Na}^{+}$and $\mathrm{Ag}^{+}$Compared. J. Chem. Phys. 2001, 115, 3454-3468.

(40) Lightstone, F. C.; Schwegler, E.; Hood, R. Q.; Gygi, F.; Galli, G. A First Principles Molecular Dynamics Simulation of the Hydrated Magnesium Ion. Chem. Phys. Lett. 2001, 343, 549-555.

(41) Bernasconi, L.; Baerends, E. J.; Sprik, M. Long-Range Solvent Effects on the Orbital Interaction Mechanism of Water Acidity Enhancement in Metal Ion Solutions: A Comparative Study of the Electronic Structure of Aqueous Mg and Zn Dications. J. Phys. Chem. B 2006, 110, 11444-11453.

(42) Blumberger, J.; Bernasconi, L.; Tavernelli, I.; Vuilleumier, R.; Sprik, M. Electronic Structure and Solvation of Copper and Silver Ions: A Theoretical Picture of a Model Aqueous Redox Reaction. J. Am. Chem. Soc. 2004, 126, 3928-3938.

(43) Guido, C. A.; Pietrucci, F.; Gallet, G. A.; Andreoni, W. The Fate of a Zwitterion in Water from $\mathrm{Ab}$ Initio Molecular Dynamics: Monoethanolamine (MEA)- $\mathrm{CO}_{2}$. J. Chem. Theory Comput. 2013, 9, $28-32$.

(44) Boero, M.; Ikeshoji, T.; Liew, C. C.; Terakura, K.; Parrinello, M.; Boero, M.; Ikeshoji, T.; Liew, C. C.; Terakura, K. Hydrogen Bond Driven Chemical Reactions: Beckmann Rearrangement of Cyclohexanone Oxime into $\varepsilon$-Caprolactam in Supercritical Water Hydrogen Bond Driven Chemical Reactions: Beckmann Rearrangement of Cyclohexanone Oxime into E-Caprolactam in Supercritical. J. Am. Chem. Soc. 2004, 126, 6280-6286.
(45) Vidossich, P.; Lledós, A.; Ujaque, G. Realistic Simulation of Organometallic Reactivities in Solution by Means of First-Principles Molecular Dynamics. In Computational Studies in Organometallic Chemistry; Macgregor, S. A., Eisenstein, O., Eds.; Structure and Bonding; Springer International Publishing: Berlin, Germany, 2016; Vol. 167, pp 81-106.

(46) Vidossich, P.; Lledós, A.; Ujaque, G. First-Principles Molecular Dynamics Studies of Organometallic Complexes and Homogeneous Catalytic Processes. Acc. Chem. Res. 2016, 49, 1271-1278.

(47) Laio, A.; VandeVondele, J.; Rothlisberger, U. A Hamiltonian Electrostatic Coupling Scheme for Hybrid Car-Parrinello Molecular Dynamics Simulations. J. Chem. Phys. 2002, 116, 6941-6947.

(48) Moret, M.-E.; Tavernelli, I.; Chergui, M.; Rothlisberger, U. Electron Localization Dynamics in the Triplet Excited State of $\left[\mathrm{Ru}(\mathrm{bpy})_{3}\right]^{2+}$ in Aqueous Solution. Chem. - Eur. J. 2010, 16, 58895894.

(49) Dal Peraro, M.; Llarrull, L. I.; Rothlisberger, U.; Vila, A. J.; Carloni, P. Water-Assisted Reaction Mechanism of Monozinc $\beta$ Lactamases. J. Am. Chem. Soc. 2004, 126, 12661-12668.

(50) Dal Peraro, M.; Vila, A. J.; Carloni, P.; Klein, M. L. Role of Zinc Content on the Catalytic Efficiency of B1Metallo $\beta$-Lactamases. J. Am. Chem. Soc. 2007, 129, 2808-2816.

(51) Cascella, M.; Magistrato, A.; Tavernelli, I.; Carloni, P.; Rothlisberger, U. Role of Protein Frame and Solvent for the Redox Properties of Azurin from Pseudomonas Aeruginosa. Proc. Natl. Acad. Sci. U. S. A. 2006, 103, 19641-19646.

(52) De Vivo, M.; Dal Peraro, M.; Klein, M. L. Phosphodiester Cleavage in Ribonuclease $\mathrm{H}$ Occurs via an Associative Two-MetalAided Catalytic Mechanism. J. Am. Chem. Soc. 2008, 130, 1095510962.

(53) Gossens, C.; Tavernelli, I.; Rothlisberger, U. Rational Design of Organo-Ruthenium Anticancer Compounds. Chimia 2005, 59, 81-84.

(54) Metz, D. J.; Glines, A. Density, Viscosity, and Dielectric Constant of Tetrahydrofuran between -78 and $30^{\circ}$. J. Phys. Chem. 1967, 71, 1158-1158.

(55) Hoover, W. G. Canonical Dynamics: Equilibrium Phase-Space Distributions. Phys. Rev. A: At., Mol., Opt. Phys. 1985, 31, 1695-1697.

(56) Martyna, G. J.; Klein, M. L.; Tuckerman, M. Nose-Hoover chains: The Canonical Ensemble via Continuous Dynamics. J. Chem. Phys. 1992, 97, 2635-2643.

(57) Nosé, S. A Unified Formulation of the Constant Temperature Molecular Dynamics Methods. J. Chem. Phys. 1984, 81, 511-519.

(58) Perdew, J. P.; Burke, K.; Ernzerhof, M. Generalized Gradient Approximation Made Simple. Phys. Rev. Lett. 1996, 77, 3865-3868.

(59) Lippert, G.; Hutter, J.; Parrinello, M. The Gaussian and Augmented-Plane-Wave Density Functional Method for Ab Initio Molecular Dynamics Simulations. Theor. Chem. Acc. 1999, 103, 124140.

(60) VandeVondele, J.; Hutter, J. Gaussian Basis Sets for Accurate Calculations on Molecular Systems in Gas and Condensed Phases. J. Chem. Phys. 2007, 127, 114105.

(61) Goedecker, S.; Teter, M.; Hutter, J. Separable Dual-Space Gaussian Pseudopotentials. Phys. Rev. B: Condens. Matter Mater. Phys. 1996, 54, 1703-1710.

(62) Grimme, S.; Antony, J.; Ehrlich, S.; Krieg, H. A Consistent and Accurate Ab Initio Parametrization of Density Functional Dispersion Correction (DFT-D) for the 94 Elements H-Pu. J. Chem. Phys. 2010, $132,154104$.

(63) Hutter, J.; Iannuzzi, M.; Schiffmann, F.; VandeVondele, J. Atomistic Simulations of Condensed Matter Systems. WIREs 2014, 4, $15-25$.

(64) Laio, A.; Gervasio, F. L. Metadynamics: a Method to Simulate Rare Events and Reconstruct the Free Energy in Biophysics, Chemistry and Material Science. Rep. Prog. Phys. 2008, 71, 126601.

(65) Laio, A.; Rodriguez-Fortea, A.; Gervasio, F. L.; Ceccarelli, M.; Parrinello, M. Assessing the Accuracy of Metadynamics. J. Phys. Chem. B 2005, 109, 6714-6721.

(66) Vandevondele, J.; Krack, M.; Mohamed, F.; Parrinello, M.; Chassaing, T.; Hutter, J. r. Quickstep: Fast and Accurate Density 
Functional Calculations Using a Mixed Gaussian and Plane Waves Approach. Comput. Phys. Commun. 2005, 167, 103-128.

(67) Krack, M.; Parrinello, M. In QUICKSTEP: Make the Atoms

Dance; NIC Series; Forschungszentrum Jülich, 2004; p 29.

(68) Humphrey, W.; Dalke, A.; Schulten, K. VMD: Visual Molecular Dynamics. J. Mol. Graphics 1996, 14, 33-38.

(69) Frisch, M. J.; Trucks, G. W.; Schlegel, H. B.; Scuseria, G. E.; Robb, M. A.; Cheeseman, J. R.; Scalmani, G.; Barone, V.; Mennucci, B.; Petersson, G. A.; et al. Gaussian 09; Gaussian, Inc.: Wallingford, CT, 2009.

(70) Hehre, W. J.; Ditchfield, R.; Pople, J. A. Self-Consistent Molecular Orbital Methods. XII. Further Extensions of GaussianType Basis Sets for Use in Molecular Orbital Studies of Organic Molecules. J. Chem. Phys. 1972, 56, 2257-2261.

(71) Clark, T.; Chandrasekhar, J.; Spitznagel, G. W.; Schleyer, P. V. R. Efficient Diffuse Function-Augmented Basis Sets for Anion Calculations. III. The 3-21+G Basis Set for First-Row Elements, LiF. J. Comput. Chem. 1983, 4, 294-301.

(72) Frisch, M. J.; Pople, J. A.; Binkley, J. S. Self-Consistent Molecular Orbital Methods 25. Supplementary Functions for Gaussian Basis Sets. J. Chem. Phys. 1984, 80, 3265.

(73) Marenich, A. V.; Cramer, C. J.; Truhlar, D. G. Universal Solvation Model Based on Solute Electron Density and on a Continuum Model of the Solvent Defined by the Bulk Dielectric Constant and Atomic Surface Tensions. J. Phys. Chem. B 2009, 113, 6378-6396.

(74) (a) Glendening, E. D.; Landis, C. R.; Weinhold, F. NBO 6.0: Natural Bond Orbital Analysis Program. J. Comput. Chem. 2013, 34, 1429-1437. (b) Glendening, E. D., Jr.; Badenhoop, K.; Reed, A. E.; Carpenter, J. E.; Bohmann, J. A.; Morales, C. M.; Landis, C. R.; Weinhold, F. NBO 6.0; Theoretical Chemistry Institute, University of Wisconsin, Madison, WI, 2013.

(75) Weinhold, F.; Landis, C. R. Discovering Chemistry with Natural Bond Orbitals; Wiley, 2012.

(76) Silverman, G. S.; Rakita, P. E. Handbook of Grignard Reagents; CRC Press: New York, 1996.

(77) Vestergren, M.; Eriksson, J.; Håkansson, M. Absolute Asymmetric Synthesis of "Chiral-at-Metal" Grignard Reagents and Transfer of the Chirality to Carbon. Chem. - Eur. J. 2003, 9, 46784686.

(78) Vestergren, M.; Eriksson, J.; Håkansson, M. Chiral cisOctahedral Grignard reagents. J. Organomet. Chem. 2003, 681, 215224.

(79) Vestergren, M.; Gustafsson, B.; Davidsson, Ö.; Håkansson, M. Octahedral Grignard Reagents Can Be Chiral at Magnesium. Angew. Chem., Int. Ed. 2000, 39, 3435-3437.

(80) Harrison-Marchand, A.; Mongin, F. Mixed AggregAte (MAA): A Single Concept for All Dipolar Organometallic Aggregates. 1. Structural Data. Chem. Rev. 2013, 113, 7470-7562.

(81) Yamazaki, S.; Yamabe, S. A Computational Study on Addition of Grignard Reagents to Carbonyl Compounds. J. Org. Chem. 2002, 67, 9346-9353.

(82) Mori, T.; Kato, S. Grignard reagents in solution: Theoretical study of the Equilibria and the Reaction with a Carbonyl Compound in Diethyl Ether Solvent. J. Phys. Chem. A 2009, 113, 6158-6165.

(83) Hölzer, B.; Hoffmann, R. W. Kumada-Corriu Coupling of Grignard reagents, Probed with a Chiral Grignard Reagent. Chem. Commun. 2003, 2, 732-733.

(84) King, A. O.; Okukado, N.; Negishi, E.-i. Highly General Stereo-, Regio-, and Chemo-Selective Synthesis of Terminal and Internal Conjugated Enynes by the Pd-Catalysed Reaction of Alkynylzinc Reagents with Alkenyl Halides. J. Chem. Soc., Chem. Commun. 1977, 683-684.

(85) Negishi, E.-i. Palladium- or Nickel-Catalyzed Cross Coupling. A New Selective Method for Carbon-Carbon Bond Formation. Acc. Chem. Res. 1982, 15, 340-348.

(86) García-Melchor, M.; Fuentes, B.; Lledós, A.; Casares, J. A.; Ujaque, G.; Espinet, P. Cationic Intermediates in the Pd-Catalyzed Negishi Coupling. Kinetic and Density Functional Theory Study of
Alternative Transmetalation Pathways in the $\mathrm{Me}-\mathrm{Me}$ Coupling of $\mathrm{ZnMe}_{2}$ and trans-[PdMeCl$\left.\left(\mathrm{PMePh}_{2}\right)_{2}\right]$. J. Am. Chem. Soc. 2011, 133, 13519-13526. 